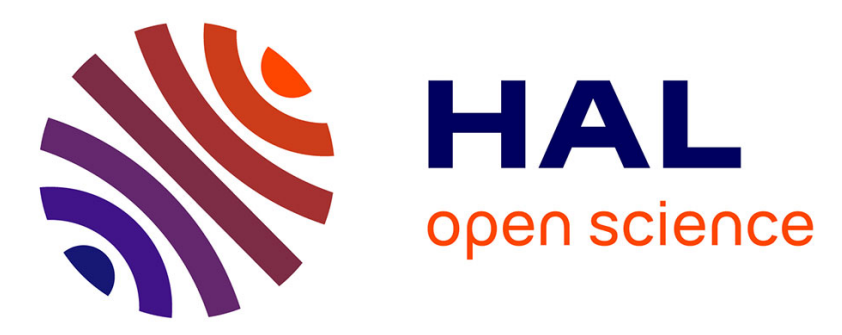

\title{
Terminal differentiation of goat mammary tissue during pregnancy requires the expression of genes involved in immune functions
}

Felicie Faucon, Emmanuelle Rebours, Claudia Bevilacqua, Jean-Christophe Helbling, Julie Aubert, Samira Makhzami, Sophie Pollet, Stephane Robin, Patrice Martin

\section{To cite this version:}

Felicie Faucon, Emmanuelle Rebours, Claudia Bevilacqua, Jean-Christophe Helbling, Julie Aubert, et al.. Terminal differentiation of goat mammary tissue during pregnancy requires the expression of genes involved in immune functions. Physiological Genomics, 2009, 40 (1), pp.61-82. hal-01193417

\section{HAL Id: hal-01193417 \\ https://hal.science/hal-01193417}

Submitted on 30 May 2020

HAL is a multi-disciplinary open access archive for the deposit and dissemination of scientific research documents, whether they are published or not. The documents may come from teaching and research institutions in France or abroad, or from public or private research centers.
L'archive ouverte pluridisciplinaire HAL, est destinée au dépôt et à la diffusion de documents scientifiques de niveau recherche, publiés ou non, émanant des établissements d'enseignement et de recherche français ou étrangers, des laboratoires publics ou privés. 


\title{
Terminal differentiation of goat mammary tissue during pregnancy requires the expression of genes involved in immune functions
}

\author{
F. Faucon, ${ }^{1,2}$ E. Rebours, ${ }^{1}$ C. Bevilacqua, ${ }^{1}$ J.-C. Helbling, ${ }^{1}$ J. Aubert, ${ }^{3}$ S. Makhzami, ${ }^{1}$ S. Dhorne-Pollet, ${ }^{1}$ \\ S. Robin, ${ }^{3}$ and P. Martin ${ }^{1}$ \\ ${ }^{1}$ Institut National de la Recherche Agronomique (INRA), Unité Mixte de Recherche (UMR) 1313, Génétique animale et \\ Biologie intégrative, équipe LGS, Jouy-en-Josas; ${ }^{2}$ Institut de l'Elevage; and ${ }^{3}$ UMR Institut National Agronomique \\ Paris-Grignon/Ecole Nationale du Génie Rural, des Eaux et des Forêts/INRA 518, Mathématiques et Informatique \\ Appliquées, Paris, France
}

Submitted 6 February 2009; accepted in final form 12 October 2009

Faucon F, Rebours E, Bevilacqua C, Helbling J-C, Aubert J, Makhzami S, Dhorne-Pollet S, Robin S, Martin P. Terminal differentiation of goat mammary tissue during pregnancy requires the expression of genes involved in immune functions. Physiol Genomics 40: 61-82, 2009. First published October 20, 2009; doi:10.1152/physiolgenomics.00032.2009.—Terminal differentiation of mammary tissue into a functional epithelium that synthesizes and secretes milk occurs during pregnancy. The molecular mechanisms underlying this complex process are poorly understood, especially in ruminants. To obtain an overview of the ruminant mammary gland's final differentiation process, we conducted time-course gene expression analysis of five physiological stages: four during pregnancy (P46, P70, P90, and P110) and one after 40 days of lactation (L40). An appropriate loop experimental design was used to follow gene expression profiles. Using three nulliparous (pregnancy) or primiparous (lactation) goats per stage, we performed a comparison starting from nine dye-swaps and using a $22 \mathrm{~K}$ bovine oligoarray. Statistical analysis revealed that the expression of 1,696 genes varied significantly at least once in the study. These genes fell into 19 clusters based on their expression profiles. Identification of biological functions with Ingenuity Pathway Analysis software revealed several similarities, in keeping with physiological stages described in mice. As in mice, expression of milk protein genes began at midpregnancy, and genes regulating lipid biosynthesis were induced at the onset of lactation. During the first half of pregnancy, the molecular signature of goat mammary tissue was characterized by the expression of genes associated with tissue remodeling and differentiation, while the second half was mainly characterized by the presence of messengers encoding genes involved in cell proliferation. A large number of immune-related genes were also induced, supporting recent speculation that mammary tissue has an original immune function, and the recruitment of migrating hematopoietic cells possibly involved in the branching morphogenesis of the mammary gland. These data hint that the induction of differentiation occurs early in pregnancy, very likely before $\mathrm{P} 46$. This period is therefore crucial for obtaining a healthy and productive mammary gland.

development; mammary gland; ruminants; gene expression profiling; innate and specific immunity

MORPHOLOGICAL DEVELOPMENT of the mammary gland begins during embryonic life with the majority of development and differentiation occurring postnatally. Isometric growth occurs in the early postnatal period followed by allometric growth phases during the prepubertal/pubertal period of mammary development in ruminant females. With the onset of pregnancy

Address for reprint requests and other correspondence: P. Martin, INRA, Génétique animale et Biologie intégrative, F-78352 Jouy-en-Josas, France (e-mail: patrice.martin@jouy.inra.fr). the mammary gland commences another round of allometric growth (25). Terminal differentiation of mammary tissue into an epithelium capable of synthesizing and secreting milk occurs only during pregnancy and is under the control of multiple hormones and paracrine factors. Progesterone, first synthesized by the ovarian corpus luteum in early pregnancy, is mainly produced by the placenta after the first third of pregnancy in women (39) and small ruminants. In the mammary gland, both steroid hormones, progesterone and estrogen, control ductal outgrowth and lobulo-alveolar expansion. Systemic effects of these hormones and interactions between their signaling pathways make the determination of their individual roles difficult. Estrogen might be a critical mediator of mammary epithelial cell (MEC) proliferation, whereas progesterone would be a stimulator of lobulo-alveolar differentiation in the pregnant gland (17). Prolactin, a pituitary hormone, triggers lactation and is essential for its maintenance. In addition it plays a crucial role in the early stage of alveolar proliferation, in mice, before apparently being replaced by placental hormones (39). Placental lactogen hormone is activated in late pregnancy and is involved in goat mammary gland development by inducing alveolar epithelial cell differentiation and proliferation $(2,22)$. Cortisol, the main bovine glucocorticoid, stimulates lobuloalveolar differentiation at parturition (60). It was recently reported that IGF-1, a local factor secreted by the stroma and/or adipocytes, after activation by growth hormone $(\mathrm{GH})$, participates in epithelial cell proliferation in heifer mammary tissue (17). Some other local factors, well described in mice and involved in mammary gland and alveolar development, such as RANKL (receptor activator of nuclear factor $\kappa \mathrm{B}$ ligand), inhibin $\beta$, TGF- $\beta$ (transforming growth factor- $\beta$ ), cyclin D1, A-myb, and C/EBP- $\beta$ (CAAT enhancer binding protein- $\beta$ ), are synthesized by epithelial cells, as well as in the stroma (reviewed in Refs. 22, 23).

After puberty, rodent mammary glands are composed of many branched ducts ending in terminal end buds (TEB) and surrounded by a mammary fat pad $(24,25)$. In rodents, lobuloalveolar growth occurs during the first third of pregnancy. The last (second) half of pregnancy is characterized by differentiation and a reduced rate of alveolar proliferation $(23,44)$. Secretory activation, which is the ultimate step of mammary gland differentiation, occurs only at parturition and is characterized by the expression of genes involved in lipid and lactose biosynthesis $(4,49)$. By contrast, there is significant expression of caseins and/or $\alpha$-lactalbumin (mRNA and proteins) in midpregnancy mammary tissue $(27,37,47,49)$. 
At the beginning of pregnancy, the ruminant mammary gland is made up of an epithelium associated with fibroblastic connective tissue and relatively few lipid-filled adipocytes (24). The mammary gland is structured by a cistern, a primary duct that branches into secondary and tertiary ducts. Clusters of ductules form so-called terminal ductule lobular units (TDLU) $(1,24,25)$. Differentiation of ruminant mammary gland into a secretory tissue during pregnancy has not been described in detail. Only one morphological description of bovine mammary development and differentiation has been reported, 30 years ago by Swanson and Poffenbarger (59). These authors showed that bovine mammary tissue already has visible lobuloalveolar structures (LAS) in midpregnancy and that these structures contain some secretory material. The mammary parenchyma develops continuously. At parturition, the secretory LAS are fully developed and occupy the entire mammary space. They contain more defined secretory material (fat globules and casein micelles). The latest studies of ruminant mammary gland development and differentiation date back more than 25 years (3). They show that mammary gland weight and DNA and RNA levels increase during pregnancy, reflecting an increase in cellular activity. Enzymatic activity increases in bovine mammary tissue several weeks before the initiation of lactation (6). Moreover, the activities of enzyme involved in lactose and fatty acid synthesis increase between 7 days prepartum and 7 days postpartum (34).

Much work has been done in recent years on mouse mammary gland development, including gene expression profiling experiments $(16,32,38,49)$. By contrast there are very few descriptions of general mechanisms and biological changes underlying ruminant mammary gland terminal differentiation during pregnancy. A first microarray analysis of cow mammary tissue shows that 16 genes are preferentially expressed during mammary gland development (57). More recently, the transition from late pregnancy to lactation (secretory switch) was shown to be characterized by downregulation of genes encoding cell proliferation factors and upregulation of genes involved in milk synthesis (20). To unravel the network of genes that participate in coordinating milk fat synthesis and secretion, Bionaz and Loor (9) quantified the expression of 45 relevant genes from the late prepartum/nonlactating period through the end of subsequent lactation. Elsewhere, expression patterns of genes that can alter mammary tissue sensitivity to galactopoietic thyroid hormones have been evaluated during the last 50 days before expected parturition and during the first weeks of lactation (11). However, global analyses of gene expression in ruminant mammary tissue at different points of the final differentiation process are lacking.

Here we report the identification of genes whose expression changes during terminal differentiation of goat mammary tissue. In addition, we used oligoarrays for gene expression profiling and longitudinal mRNA expression analysis during the course of pregnancy in an attempt to unravel gene networks and further understand the mechanisms by which goat mammary tissue acquires its secretory phenotype. Our results strongly suggest that mammary gland terminal differentiation during pregnancy, which is a period of intensive tissue remodeling, also requires, as demonstrated for involution $(5,16,56)$, the expression of immune-related genes.

\section{MATERIALS AND METHODS}

Animals and tissue sampling. Pregnant or primiparous lactating Saanen or Alpine goats from an INRA experimental farm (UE325, UCEA Brouessy, Magny-Les-Hameaux, France), were euthanized, immediately after milking, in safe and painless conditions, in compliance with the INRA Animal Care Committee guidelines. At slaughter, mammary glands were removed quickly (within 2-3 min), and pieces $(5-10 \mathrm{~g})$ of mammary parenchymal tissue were carefully taken for isolation of RNA, under sterile conditions, in a zone located in the middle of the parenchymal area, excluding peripheric stromal tissue. Approximately $1-\mathrm{cm}^{3}$ tissue blocks were washed in ice-cold saline to remove residual milk and then immediately frozen into liquid nitrogen and stored at $-80^{\circ} \mathrm{C}$ until further processing. We studied five different developmental stages of mammary epithelium, hereafter called "time points," corresponding to 46, 70, 90, and 110 days of pregnancy and 40 days of lactation and designated P46, P70, P90, P110, and L40, respectively. Given parenchymal mammary tissue was scarce and highly heterogeneous in early pregnancy (P46), no morphological and/or biochemical controls for tissue type collected were performed. Mammary glands from three different goats were used to characterize each stage of pregnancy or lactation, to reduce the impact of individual variability.

RNA extraction. Frozen mammary tissue samples were ground in liquid nitrogen with a Freezer Mill 6750 (Fisher Scientific Bioblock). Total RNA was extracted by mixing the resulting powder with TRIzol reagent following the manufacturer's instructions (Invitrogen, CergyPontoise, France). The resulting aqueous phase of each sample was purified on QIAGEN RNeasy mini-columns. After DNaseI treatment (Qiagen SA, Courtaboeuf, France) total RNA was eluted and concentration was determined as the $260 / 280 \mathrm{~nm}$ OD ratio with a Nanodrop ND-1000 spectrophotometer (Nanodrop Technology, Nyxor Biotech). The quality of each RNA sample was evaluated on an Agilent 2100 Bioanalyzer with 6000 Nano LabChip kits (Agilent Technologies). Samples with an RNA integrity number (RIN) factor $(52)<7.5$ were discarded.

RNA labeling. RNA samples were labeled using the Superscript Plus Indirect cDNA labeling protocol (Invitrogen) according to the manufacturer's instructions. Briefly, $10 \mu \mathrm{g}$ of total RNA was first reverse transcribed using SuperScript III Reverse Transcriptase and converted into aminoallyl cDNAs, which were separated from nonincorporated amino-modified dNTPs on S.N.A.P. columns. They were then labeled with $\mathrm{Cy} 3$ or $\mathrm{Cy} 5$ dyes (Amersham Bioscience, GE Healthcare Europe, Saclay, France) and subsequently separated from non-incorporated dyes on S.N.A.P. columns. Frequencies of dye incorporation (FOI, rate per thousand labeled nucleotides) and cDNA concentrations were estimated for both dyes by measuring the absorbance at $260 \mathrm{~nm}, 550 \mathrm{~nm}$ and $650 \mathrm{~nm}$ on a Nanodrop spectrophotometer (Nyxor Biotech). The following ratios were calculated: FOI $(\mathrm{Cy} 3)=($ Abs550 $\times 324.5) /($ Abs $260 \times 5.55)$, FOI $(\mathrm{Cy} 5)=($ Abs650 $\times$ $324.5) /($ Abs $260 \times 9.25)$ and an upper limit of 20 was chosen to retain labeled cDNA samples for further analysis. Cyanine incorporation was finally checked by scanning, with a Typhoon 9410 imager (GE Healthcare), $1 \%$ agarose gels on which fluorescently labeled cDNAs had been resolved by electrophoresis.

Microarray processing and data analysis. Since goat microarrays were not available, we used a heterologous system, i.e., an oligoarray developed for a closely related species (bovine), for gene expression profiling. Such an approach has already been successfully used to study the impact of different genotypes occurring at the CSN1S1 locus (encoding $\alpha_{\mathrm{s} 1}$-casein) on the goat mammary transcriptome (42). Microarrays used in this study were $22 \mathrm{~K}$ bovine oligonucleotide probe arrays [National Center for Biotechnology Information (NCBI) Gene Expression Omnibus (GEO): 6694] spotted by Centre de Ressources Biologiques - Génomique des Animaux Domestiques et d'Intérêt Economique (CRB-GADIE, INRA, Jouy-en-Josas, France). Of the 23,232 probes spotted on the slides, 960 were empty spots, 260 were 
spots containing buffer, 8,709 spots were oligonucleotides from the Bovine Genome Oligoset V1.1 (Operon Biotechnologies), and 13,303 spots were oligonucleotides from a pre-existing set (NCBI GEO: GPL2853), developed from a bovine embryo cDNA library (19). These two bovine oligonucleotide sets are identified hereafter as "Operon" and "Illumina" sets, respectively.

Prior to hybridization, microarrays were prehybridized for $30 \mathrm{~min}$ at $50^{\circ} \mathrm{C}$ in a filtered solution of $1 \% \mathrm{BSA}, 3.5 \times \mathrm{SSC}, 0.1 \%$ SDS and rinsed twice in ultrapure water for $5 \mathrm{~min}$ with orbital agitation. Each microarray was cohybridized with two fluorescently labeled (Cy3 and Cy5) cDNA samples. An evaluated amount of $380 \mathrm{ng}$ of each labeled cDNA was fragmented for $30 \mathrm{~min}$ at $60^{\circ} \mathrm{C}$ in $1 \times$ fragmentation buffer (Agilent Technologies). Then, fragmented labeled cDNA samples were diluted in Agilent hybridization buffer and hybridized on the $22 \mathrm{~K}$ bovine oligoarray for $20 \mathrm{~h}$ at $60^{\circ} \mathrm{C}$ in a rotating hybridization oven (Agilent Technologies).

An even-loop experimental design (Fig. 1) was developed based on variance minimization $(28,29)$. In this experimental design, every time point was compared with the four others in nine dye-swaps, except for the comparison between the most distant time points (P46 and L40). One dye-swap corresponded to one comparison, meaning two slides.

After hybridization, microarrays were washed twice with orbital agitation for $5 \mathrm{~min}$ at $50^{\circ} \mathrm{C}$ in $2 \times \mathrm{SSC}-0.1 \% \mathrm{SDS}$ and were then successively washed twice at room temperature in $(0.5 \times \mathrm{SSC}, 0.1 \%$ SDS) solution for $5 \mathrm{~min},(0.1 \times \mathrm{SSC}, 0.1 \% \mathrm{SDS})$ solution for $5 \mathrm{~min}$, $(0.1 \times \mathrm{SSC})$ solution three times for $5 \mathrm{~min}$, and in ultrapure water for $1 \mathrm{~min}$. They were finally dried for $45 \mathrm{~s}$ in a minicentrifuge system.

Microarrays were scanned on an Agilent scanner (Agilent Technologies) at a $10 \mu \mathrm{m} \times 10 \mu \mathrm{m}$ pixel resolution. Agilent Feature Extraction 9.1.3.1 software (Agilent Technologies) was used to quantify mean and median signals for each sample and for background estimation following the GE2_NonAgilent_91 extraction protocol. Extracted data were stored in the BioArray Software Environment (BASE) of SIGENAE (Système d'Information des GENomes des Animaux d'Elevage) 2008 (//www.sigenae.org) and then formatted according to MIAME standards (10). The data have been submitted to
NCBI's GEO database as series GSE14008 (//www.ncbi.nlm.nih. gov/geo/query/acc.cgi?token $=$ jrqrhioqcywkmtc\&acc $=$ GSE14008), and were analyzed with $\mathrm{R}$ Program Writer software (//www.r-project. org/).

Statistical analyses. Data were normalized using the "normalisation" function of the "anapuce" $\mathrm{R}$ package, based on an intensitydependent procedure with a global lowess (64) followed by subtraction of the log-ratio median calculated over the values for an entire block from each individual log-ratio to correct for a possible print-tip effect.

First, we calculated the average normalized signal for each spot at every time point. The most strongly expressed genes were selected when the corresponding spot signal intensity represented, at a given time point, $>10 \%$ of the most intense signal observed. Genes that were globally highly expressed at every time point were also selected.

In a second analysis, experimental normalized data extracted from the microarrays of dye-swaps S1, S4, S7, and S9 (Fig. 1) were compared between pairs of time points, as follows: P46 with P70 (P46/P70), P70 with P90 (P70/P90), P90 with P110 (P90/P110) and P110 with L40 (P110/L40), respectively. Differential analysis with variance mixture modeling (18), based on the "DiffAnalysis" function developed in the anapuce package of $\mathrm{R}$, was performed on the normalized data set. This method builds up groups of genes with homogeneous variance. To take into account the multiplicity of tests, $P$ values were adjusted with the Benjamini-Hochberg procedure (7) which controls the false discovery rate (FDR) with a significance threshold set at $5 \%$.

In the third analysis, the entire data set was analyzed with a linear model that included a stage effect. We used the covariance matrix of the parameter estimates to calculate the variance of all contrasts between successive stages $\mu_{\mathrm{i}+1}-\mu_{\mathrm{i}}$ and assessed their significance with a $t$-test. $P$ values were corrected with the Benjamini-Hochberg procedure (7). Genes whose expression varied significantly at least once during pregnancy and lactation were clustered using the KMC (K-means clustering) function of TMeV v4.0 software $(51,55)$. KMC was considered appropriate as it builds homogeneous clusters by characterizing each cluster with a central point (its mean), assigning

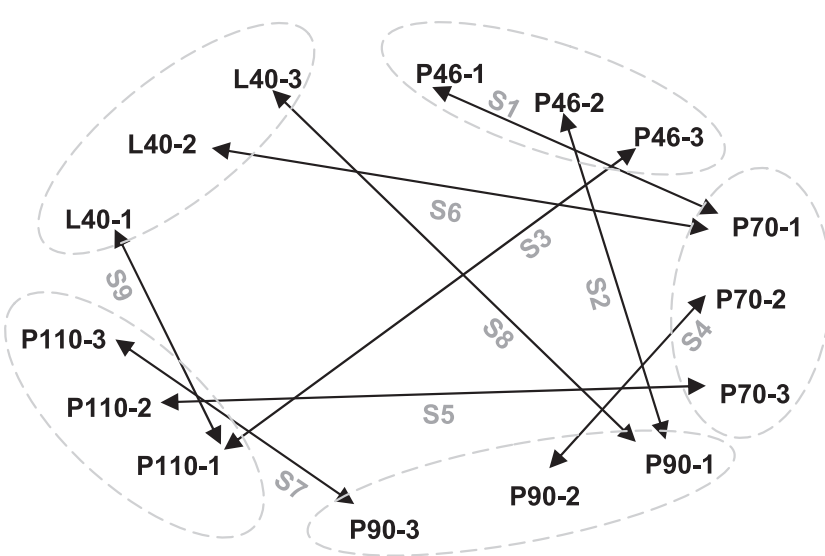

\begin{tabular}{|c|c|c|c|}
\hline $\begin{array}{l}\text { Dye- } \\
\text { Swap }\end{array}$ & Slide & $\begin{array}{l}\text { Time point } \\
\text { in Cy } 3\end{array}$ & $\begin{array}{l}\text { Time point } \\
\text { in Cy5 }\end{array}$ \\
\hline \multirow[t]{2}{*}{1} & & P46 & P70. \\
\hline & S2 & P70 & P46 \\
\hline \multirow[t]{2}{*}{2} & S3 & P46 & P90 \\
\hline & $\mathrm{S} 4$ & P90 & P46 \\
\hline \multirow[t]{2}{*}{3} & S5 & P46 & P110 \\
\hline & S6 & P110 & P46 \\
\hline \multirow[t]{2}{*}{4} & S7 & P70 & P90 \\
\hline & S8 & P90 & P70 \\
\hline \multirow[t]{2}{*}{5} & S9 & P70 & P110 \\
\hline & $\mathrm{S} 10$ & P110 & P70 \\
\hline \multirow[t]{2}{*}{6} & S11 & P70 & L40 \\
\hline & $\mathrm{S} 12$ & L40 & P70 \\
\hline \multirow[t]{2}{*}{7} & $\mathrm{~S} 13$ & P90 & P110 \\
\hline & S14 & P110 & P90 \\
\hline \multirow[t]{2}{*}{8} & S15 & P90 & L40 \\
\hline & S16 & L40 & P90 \\
\hline \multirow[t]{2}{*}{9} & S17 & P110 & L40 \\
\hline & S18 & L40 & P110 \\
\hline
\end{tabular}

Fig. 1. Loop experimental design and hybridization table. P, pregnancy; L, lactation. 
each gene to the closest cluster, and recalculating the mean of the cluster (31). The parameters used to build the clusters were the Euclidean distance and a maximum of 50 iterations.

General slide information and probe annotation. To recover GenBank accession numbers and human references for each probe on the slide, we used a web-accessible resource established by SIGENAE (http://public-contigbrowser.sigenae.org:9090/Bos_taurus/index.html), selecting either Human Unigene or SwissProt filters. To annotate the probes in this contig browser (BioMart), the SIGENAE tool first compared the 70 mer oligonucleotide sequences spotted on the slide with the latest version of the bovine genome assembling (Cattle V8 s.bt. 8 based on p.bt.5 published in November 2007). If the 70 mer oligonucleotide sequence matched the bovine assembling perfectly at a single place, then the annotation associated with this locus was directly selected to annotate the probe. If the match was imperfect, the 70 mer oligonucleotide sequence was compared with all Ensembl transcripts and the retained probe annotation corresponded to the contig number that contained the sequence.

Among the 22,012 oligonucleotide sequences spotted on the glass slides, 416 were control spots and 21,596 corresponded to different sequences. Among these 21,596 sequences, 14,687 ( 68\%) had a human reference accepted by Ingenuity Pathway Analysis software v6.0 (IPA, Ingenuity Systems, Redwood City, CA). Of these 14,687 "IPA genes," 4,714 ( 32\%) were redundant between the Operon and Illumina sets. In other words, with $\sim 17,000$ UniGene clusters $(9,973$ different genes analyzed in IPA and $\sim 7,000$ probes with Sigenae's annotation not accepted by IPA), the oligoarray platform used in this study represents a meaningful bovine gene repertoire.

Identification of biological functions. For each analysis, significant data were referenced to biological functions with IPA software. The contribution of genes to the identified function was explained with an associated $P$ value, calculated with the right-tailed Fisher's exact test. In this test the number of user-specified genes of interest that participated in a given function or pathway was compared with the total number of occurrences of these genes in all functional/pathway annotations stored in the Ingenuity Pathways Knowledge Base. Only significant top IPA molecular and cellular functions and IPA physiological system development and functions $(P$ value $<5 \%)$ are presented and discussed in this article.

Primer design and quantitative real-time PCR. Total RNA $(1 \mu \mathrm{g})$ was reversed transcribed with $0.5 \mu \mathrm{g}$ of Oligo(dT)12-18 primer and SuperScript III (Invitrogen). The quantitative real-time PCR (qPCR) was carried out as described by Bevilacqua et al. (8), using the SYBR Green PCR Master mix and the ABI Prism 7900 Sequence Detection System (Applied Biosystems, Foster City, CA) to measure mRNA abundance. A total of 24 genes were validated by qPCR, using three potential reference genes, cyclophilin A, 18S ribosomal RNA and S24 ribosomal protein (RPS24), as internal controls. As previously reported (8), RPS24 mRNA was chosen as the internal control. Primer pairs shown in Table 1 were designed using Primer Express Applied Biosystems software v2.0 (Applied Biosystems, France), starting from publicly available caprine and bovine sequences. To avoid genomic DNA amplification, primers were primarily selected on exon-exon splice boundaries of goat messenger sequences, when available, or otherwise from bovine sequences. Primers were purchased from MWG Biotech (France).

All melt curves showed a single amplicon and the specificity of most of the qPCR assays was confirmed by amplicon sizing and sequencing. Amplification efficiency was measured for each system and differences in gene expression were analyzed using one-way ANOVA with a threshold of significance set at $P<0.01$.

To compare the expression profile of selected genes in qPCR and microarray experiments, we first normalized (with RPS24 transcripts as internal control) individual qPCR data. Relative abundances of target transcripts at the different stages of pregnancy were determined, assuming the expression of individual lactation was 1,000. The same procedure was applied to microarray data, except that normalization was performed as described above. Then the mean and standard deviation for each developmental stage were calculated and bar charts were drawn.

Preparation of thin mammary tissue sections for histology. For histological studies, dissected samples of mammary tissue, taken at the indicated time points, were washed immediately after collection in cold PBS, cut into cubes 3-4 mm thick, embedded in OCT (TissuTek), placed in cryomolds of $1 \mathrm{~cm}^{3}$ (Bayer) and immediately immerged in liquid nitrogen. Samples were stored at $-80^{\circ} \mathrm{C}$ until further processing. Mammary tissue sections $(8 \mu \mathrm{m})$ were obtained for histological analysis by using a cryostat (Thermo Shandon, France) and were then stained with hematoxylin for $30 \mathrm{~s}$ and dehydrated through a graded series of ethanol solutions: $1 \mathrm{~min}$ in $75 \%$ ethanol, twice $1 \mathrm{~min}$ in $95 \%$ ethanol, twice $1 \mathrm{~min}$ in $100 \%$ ethanol anhydrous (Fluka, Sigma-Aldrich, Lyon, France).

\section{RESULTS}

Three independent analyses of the microarray data were performed. In each we determined the most relevant $P$ value based on experiments previously carried out in our laboratory (unpublished results) and the statistical methods used. The three independent analyses were the following: 1) extraction of the most highly expressed genes at each developmental stage, 2) identification of genes whose expression varied between two successive time points, and 3) clustering of genes sharing the same expression profile, from 46 days of pregnancy (P46) to 40 days of lactation (L40). In addition, expression profiles of relevant genes identified by microarray analyses were validated with qPCR.

The most highly expressed genes at each developmental stage. To obtain an overview of genes highly expressed at each developmental stage, we selected spots with signals $>10 \%$ of the highest signal on each array. The number of highly expressed genes was relatively constant throughout pregnancy (Table 2), ranging between 130 (L40) and 175 (P90). ${ }^{1}$

Eighty-two probes were common to all time points (Table 3). They corresponded to 48 different genes with known identifiers that mapped to their corresponding gene object in the Ingenuity Pathways Knowledge Base. These genes were overlaid onto a global molecular network built from information contained in the database. They were representative of the following molecular and cellular functions: cell cycling, cell morphology, posttranslational modification, cell death, and cell signaling. Some of these genes have been shown to be involved in apoptosis, such as BAX (BCL-2 associated X-protein), BCL-2 (B-cell leukemia/lymphoma 2) and STAT3 (signal transducer and activator of transcription 3), which were highly expressed at every developmental stage. They are known to participate in apoptosis and differentiation of macrophages. Other genes such as HMGA1 (high mobility group AT-hook 1), ZAK (sterile alpha motif and leucine zipper containing kinase AZK) and EEF1A1 (eukaryotic translation elongation factor $1 \alpha 1$ ) that are regulators of transcription and translation also belonged to this set. Likewise, RHOC (ras homolog gene family, member $\mathrm{C}$ ), which promotes reorganization of the actin cytoskeleton and regulates cell shape attachment and motility showed high signal intensity at every developmental stage. EGFL7 (EGF-like-domain, multiple 7), which behaved like-

\footnotetext{
${ }^{1}$ The online version of this article contains supplemental material.
} 
Table 1. Oligonucleotide primers used in this study

\begin{tabular}{|c|c|c|c|c|c|c|c|c|c|c|}
\hline$\frac{\text { Genes }}{\alpha \text { s1-casein }(C S N 1 S 1)}$ & \multirow{2}{*}{$\begin{array}{l}\text { Primers } \\
\begin{array}{l}\text { forward } \\
\text { reverse }\end{array}\end{array}$} & \multicolumn{8}{|c|}{ Sequence $5^{\prime}>3^{\prime}$} & $\frac{\text { Amplicon Size, } \mathrm{n}}{61}$ \\
\hline & & GCC & $\mathrm{AAT}$ & GGG & $\mathrm{ATT}$ & AGG & GAT & GTC & & \\
\hline$\alpha \mathrm{s} 2$-casein $(C S N 1 S 2)$ & forward & CTG & GTT & ATG & GTT & GGA & CTG & GAAA & & 76 \\
\hline \multirow[t]{2}{*}{$\beta$-casein $(C S N 2)$} & forward & GAA & AGC & CAG & AGC & CTG & $\mathrm{ACT}$ & CTC & A & 63 \\
\hline & reverse & CTG & GAC & CAG & AGC & CAG & AGG & AA & & \\
\hline $\mathrm{\kappa}$-casein $(C S N 3)$ & forward & AGG & TGC & $\mathrm{AAT}$ & GAT & GAA & GAG & TTT & TTT C & 66 \\
\hline \multirow[t]{2}{*}{$\beta$-lactoglobulin $(B L G)$} & forward & CAT & CGT & $\mathrm{CAC}$ & CCA & GAC & CAT & GA & & 54 \\
\hline & reverse & CAA & GTC & $\mathrm{CCC}$ & GCC & $\mathrm{ACC}$ & TTC & & & \\
\hline \multirow[t]{2}{*}{ Lactoferrin $(L T F)$} & forward & GAG & $\mathrm{ACC}$ & $\mathrm{AAC}$ & GGA & AGG & GTA & $\mathrm{CCT}$ & & 59 \\
\hline & reverse & TGA & GCC & $\mathrm{CCT}$ & $\mathrm{CAT}$ & TTG & CTT & $\mathrm{TC}$ & & \\
\hline \multirow[t]{2}{*}{ Osteopontin $(O P N)$} & forward & $\mathrm{CCC}$ & AGG & AGG & AGA & GCA & $\mathrm{AGC}$ & ATT & & 66 \\
\hline & reverse & TCT & TGG & $\mathrm{CTG}$ & AGT & TTG & GAA & TTT & $\mathrm{TC}$ & \\
\hline & reverse & GCA & GGA & GTG & GAA & GAG & $\mathrm{CCA}$ & GTA & & \\
\hline \multirow[t]{2}{*}{ Stearoyl CoA desaturase $(S C D)$} & forward & TGC & TGA & CAA & $\mathrm{CTT}$ & ATC & TGG & ATG & $\mathrm{C}$ & 178 \\
\hline & reverse & $\mathrm{AAG}$ & GAA & $\mathrm{TC} \mathrm{T}$ & TGC A & AAA C & CAG C & CTA & & \\
\hline Fatty acid synthase $(F A S N)$ & forward & ACA & GCC & TCT & TCC & TGT & TTG & ACG & & 225 \\
\hline & reverse & CTC & TGC & ACG & ATC & $\mathrm{AGC}$ & TCG & $\mathrm{AC}$ & & \\
\hline Adipophilin $(A D R P)$ & forward & $\mathrm{CCC}$ & $\mathrm{ACT}$ & GTG & CTG & AGC & $\mathrm{ACA}$ & $\mathrm{TT}$ & & 57 \\
\hline & reverse & GAG & TCA & GGT & TCC & GGG & CAA & $\mathrm{T}$ & & \\
\hline FABP-4 & forward & TGG & TGC & TGG & $\mathrm{AAT}$ & GTG & TCA & TGA & & 63 \\
\hline & reverse & TGG & $\mathrm{CTT}$ & ATG & CTC & TCT & CGT & AAA & CTC T & \\
\hline BMP-7 & forward & $\mathrm{AAG}$ & $\mathrm{CAC}$ & GAG & CTA & TAC & GTC & $\mathrm{AGC}$ & $\mathrm{TT}$ & 62 \\
\hline & reverse & TCG & GGT & GCG & ATG & $\mathrm{ATC}$ & $\mathrm{CA}$ & & & \\
\hline ID-2 & forward & GAA & GGT & GAG & CAA & GAT & GGA & $\mathrm{AAT}$ & $\mathrm{CC}$ & 191 \\
\hline & reverse & GGA & $\mathrm{ATT}$ & CAG & AAG & CCT & GCA & AGG & $\mathrm{AC}$ & \\
\hline & reverse & CGT & GGA & TCT & $\mathrm{AAT}$ & TCA & ATG & TTG & TAT TTG & \\
\hline Keratin $14(K R T-14)$ & forward & CCC & AGC & TCA & GCA & TGA & AAG & $\mathrm{C}$ & & 57 \\
\hline & reverse & AGC & GGC & СТT & TGG & TCT & СTT & $\mathrm{C}$ & & \\
\hline Insulin-like growth factor binding protein 5 & forward & $\mathrm{CAC}$ & $\mathrm{AGT}$ & AGC & CCA & CAC & GGA & TAG & A & 66 \\
\hline$(I G F B P 5)$ & reverse & ATT & CCG & $\mathrm{AGT}$ & TGC & CTA & CCG & G & & \\
\hline Lipin 1 (LPIN1) & forward & $\mathrm{CCC}$ & TTC & TAT & GCT & GCT & TTT & GGA & & 64 \\
\hline & reverse & TCG & TAC & AAG & CAA & GTG & GGA & GTG & $\mathrm{T}$ & \\
\hline ATP-binding cassette, subfamily G (White), & forward & CAT & TCC & TCG & ATA & CGG & CTA & TGC & & 63 \\
\hline member $2 *(A B C G 2)$ & reverse & TTT & GGG & ACA & AAA & СTT & CTG & $\mathrm{CCC}$ & & \\
\hline Chemokine (C-X-C motif) ligand $9 *(C X C L 9)$ & forward & GGG & CTT & GGA & AAC & CCT & CTT & AAA & & 61 \\
\hline & reverse & GCA & TAA & GAG & AGG & ATG & TCA & GGC & $\mathrm{CA}$ & \\
\hline $24 \mathrm{~S}$ ribosomal protein $(R P S 24)$ & forward & TTT & GCC & AGC & $\mathrm{ACC}$ & AAC & GTT & G & & 66 \\
\hline & reverse & AAG & GAA & CGC & AAG & AAC & AGA & ATG & AA & \\
\hline
\end{tabular}

Each pair of primers amplifies the target cDNA (amplicon sizes ranging between 54 and 225 nucleotides). Primers pairs were designed with Primer Express Software v2.0 (Applied Biosystems) except for $24 \mathrm{~S}$ ribosomal protein primers, which were manually designed. *Unoptimized qPCR system.

wise, is involved in the establishment and maintenance of endothelial integrity (angiogenesis).

These results show that the goat mammary gland, during pregnancy and lactation, is a very dynamic organ requiring remodeling and high cell turnover. High signal intensities were noted in pregnancy and lactation for genes involved in apoptosis and cellular organization and in regulating transcription and translation. The presence of two casein-encod- ing genes (CSN2 and CSN3) in this dataset was unexpected, especially in view of their high signal intensity at every stage of pregnancy.

In addition, the protein synthesis function, here mainly represented by genes coding for ribosomal proteins (RPLs), was associated with every stage of pregnancy. Surprisingly, this biological function is not associated with lactation, despite this being a period of intense milk protein biosynthesis. 
Table 2. IPA molecular and cellular function of gene sets enriched with the most strongly expressed genes at each developmental stage

\begin{tabular}{|c|c|c|c|}
\hline $\begin{array}{l}\text { Developmental } \\
\text { Stage }\end{array}$ & $\begin{array}{c}\text { Probes With } \\
\text { Signals Within } \\
10 \% \text { of the } \\
\text { Highest Signal, } n\end{array}$ & $\begin{array}{c}\text { Probes With IPA } \\
\text { Annotation (no. } \\
\text { of probes } \\
\text { without IPA } \\
\text { annotation), } n\end{array}$ & $\begin{array}{c}\text { Ingenuity } \\
\text { Molecular and } \\
\text { Cellular Function }\end{array}$ \\
\hline P46 & 152 & $78(49)$ & $\begin{array}{l}\text { protein synthesis } \\
\text { cell cycle } \\
\text { cell morphology } \\
\text { PTM } \\
\text { cell death }\end{array}$ \\
\hline P70 & 169 & $87(50)$ & $\begin{array}{l}\text { protein synthesis } \\
\text { cell death } \\
\text { cell cycle } \\
\text { cell morphology } \\
\text { PTM }\end{array}$ \\
\hline P90 & 175 & $92(53)$ & $\begin{array}{l}\text { protein synthesis } \\
\text { cell death } \\
\text { cell cycle } \\
\text { cell movement } \\
\text { cell morphology }\end{array}$ \\
\hline P110 & 153 & $82(45)$ & $\begin{array}{l}\text { protein synthesis } \\
\text { cell death } \\
\text { cell cycle } \\
\text { cell morphology } \\
\text { PTM }\end{array}$ \\
\hline L40 & 130 & $79(40)$ & $\begin{array}{l}\text { cell death } \\
\text { cell cycle } \\
\text { cell morphology } \\
\text { PTM } \\
\text { cell signaling }\end{array}$ \\
\hline
\end{tabular}

Boldface indicates functions that are common to all developmental stages. L, lactation; P, pregnancy; PTM, posttranslational modification. Lists of the most highly expressed genes at each developmental stage are provided in Supplemental data files highly_expressed_genes_P46, highly_expressed_genes_P70, highly_expressed_ genes_P90, highly_expressed_genes_P110, highly_expressed_genes_L40.

Comparisons between successive time points. To evaluate differences between two successive developmental stages, four differential analyses were carried out. The first compared 46 and 70 days of pregnancy (P46/P70), the next was aimed at identifying differentially expressed genes (DEG) between 70 and 90 days of pregnancy (P70/P90), the third compared 90 and 110 days of pregnancy (P90/P110), and the last compared 110 days of pregnancy and 40 days of lactation (P110/L40). The number of DEGs ( $P$ values adjusted using the BenjaminiHochberg method with a threshold of FDR of 5\%) between two successive time points gave the first quantitative indication of differences. There were 2,566 genes differentially expressed between P46 and P70, 448 between P110 and L40, 35 between P70 and P90, and 30 between P90 and P110 (Table 4, also see supplemental material). These figures illustrate the deep functional recasting occurring during pregnancy, especially in early stages and after parturition. This is consistent with the notion that P46, which represents early pregnancy, and L40, which corresponds to established lactation, are extreme developmental stages both very different from the other three stages of pregnancy.

Regarding the P46/P70 comparison, the lowest fold change was 1.4 (210 probes) and the highest 177, corresponding to $\kappa$-casein (CSN3), the expression of which increased between P46 and P70. On the other hand, the expression of IGFBP3 (insulin-like growth factor binding protein 3), a protein which affects cell growth by positively regulating apoptosis and myoblast differentiation and by negatively regulating protein phosphorylation and signal transduction, decreased between P46 and P70. Other genes whose expression decreased between P46 and P70 included COL3A1 (collagen, type III, alpha 1), DCN (decorin), OGN (osteoglycin), PLXNB3 (plexin B3), which participate in organ morphogenesis. Genes whose expression increased between P46 and P70 were mainly involved in immune functions [guanylate binding protein 5 (GBP5), lipopolysaccharide binding protein (LBP), chemokine, C-C motif, ligand 4 (CCL4), immunoglobulin heavy constant alpha 1 (IGHA1) and lactoferrin (LTF)], molecular transport [ubiquitin D (UBD) and retinol binding protein 1 (RBP1)] and cell movement [serpin peptidase inhibitor, clade E (SERPINE2)]. Thus, genes involved in organ morphogenesis showed decreased expression between P46 and P70, whereas the expression of immune response genes increased.

Few genes were differentially expressed between P70 and P90, and only eight genes were upregulated during this period. Twenty-one genes were downregulated, with fold changes ranging between 3.5 and 39 , for the genes encoding lactoferrin (LTF) and $\alpha_{\mathrm{s} 2}$-casein (CSN1S2), respectively. The same tendency was observed with genes involved in the immune response, including IFI6 (interferon, alpha-inducible protein 6), IFI44L (interferon-induced protein 44-like), and CXCL10 (chemokine, C-X-C motif, ligand 10), as well as BoLA-A, which is a component of the bovine major histocompatibility complex (MHC). CSN3 downregulation between P70 and P90, revealed by the analysis of the most highly expressed genes (Table 3), was confirmed in this comparison.

Again, few genes were differentially expressed between P90 and P110 $(n=30)$; they included genes involved in the regulation of transcription and protein synthesis [ mutL homolog 1 (MLH1), synovial apoptosis inhibitor 1 or synoviolin (SYVN1), and heat shock $70 \mathrm{kDa}$ protein 1B (HSPA1B)], which showed decreased expression between P90 and P110. FHOD1 (formin homology 2 domain containing 1) and INHA (inhibin alpha), which participate in cellular organization, showed the same behavior. Some genes upregulated between P90 and P110 are known to be involved in immune responses, including: BoLA-DGA1, BoLA-A, CXCL9 (chemokine, CX-C motif, ligand 9), GBP5, MBP (myelin basic protein), as well as LTF and TPM3 (tropomyosin 3), which regulates cell motility. During this part of pregnancy, fold changes ranged from 3.2 to 15 , respectively for the guanine nucleotide binding protein (GNA13) gene, whose expression decreased, and the major histocompatibility complex (BoLA-DQA1) gene, whose expression increased from $\mathrm{P} 90$ to $\mathrm{P} 110$, reflecting adjustments rather than deep changes in the gene expression profile.

The transition from late pregnancy to early established lactation (P110/L40) showed once more that the expression of genes involved in immune response (BoLA-A, GBP5), chemoattractant cytokines promoting $\mathrm{T}$ cell adhesion to endothelial cells (CXCL9 and CXCL10), and VCAM (vascular cell adhesion molecule 1) which is upregulated by cytokines in endothelial cells, decreased from P110 to L40 (Table 5). In contrast, genes involved in lipid metabolism and secretion [ lipoprotein lipase (LPL), butyrophilin (BTN1A1), stearoylCoA-desaturase (SCD), and fatty acid binding protein 3 (FABP3)], molecular transport [(NCALD) neurocalcin delta; NADH dehydrogenase, ubiquinone, 1 beta subcomplex, 8, 19 
Table 3. 82 probes with high signal intensity at each developmental stage

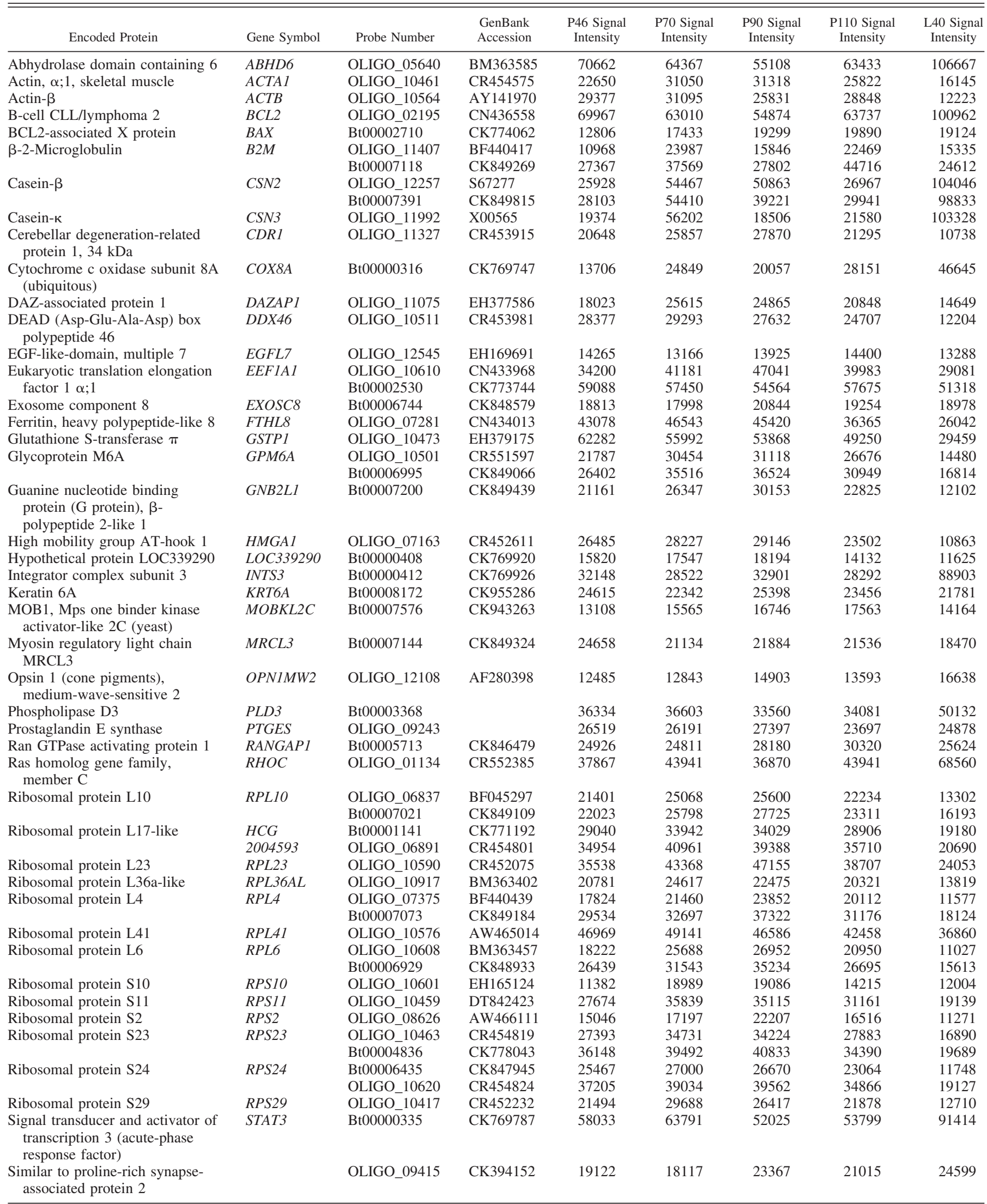


Table 3.-Continued

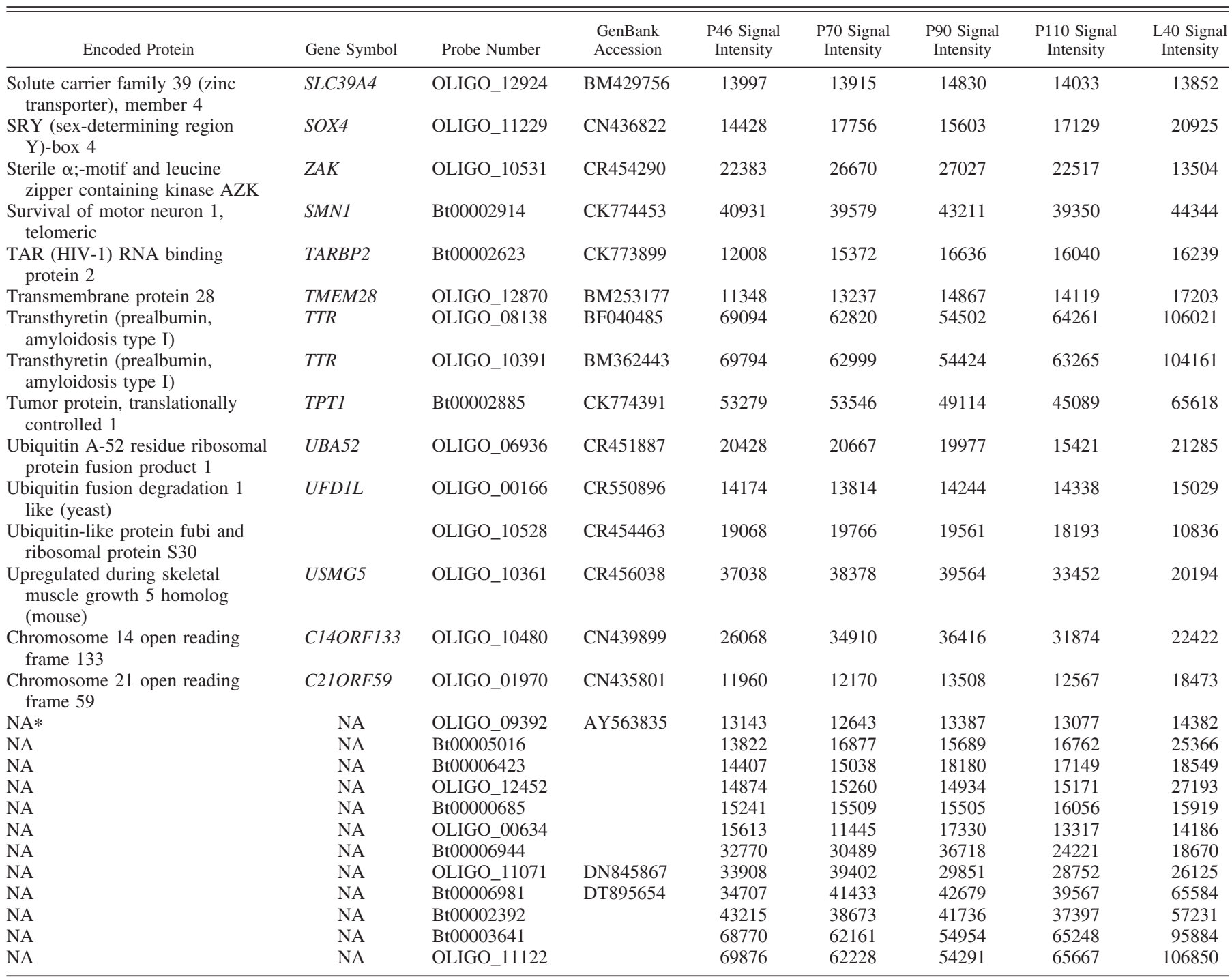

*NA, probes with no annotation.

kDa (NDUFB8); and nucleoporin 107 kDa (NUP107)], and protein folding [DnaJ homolog, subfamily $\mathrm{C}$, member 12 (JDP-1)] were upregulated. This was also the case for milk protein genes: $\alpha_{\mathrm{s}^{-}}, \alpha_{\mathrm{s}^{2}}$ and $\beta$-caseins (CSN1S1, CSN1S2, and CNS2) and $\alpha$-lactalbumin (LALBA). The CSN3 gene follows the same trend which is significant at a slightly higher FDR threshold $(6 \%)$. Fold changes ranged from -17.7 (UBD) to 360 (CNS1S1). Finally, while biological functions characterizing late pregnancy are immune response and cell adhesion, lactation is described by lipid metabolism, molecular transport, and milk protein synthesis and protein folding.

Clustering. To better characterize the biological significance of each gene expression profile, we sought clusters of genes that varied significantly at least once in the linear model analysis. In this analysis, the $t$-test applied to the contrasts between estimated parameters allowed us to conclude that 2,330 probes corresponding to 1,696 different genes with IPA annotation varied significantly $(P$ values adjusted using the Benjamini-Hochberg method with a threshold of FDR of 15\%) at least once in the study. We set the significance threshold at
0.15 to recover a maximum of genes of interest, such as genes coding for milk proteins, which showed significant variations by quantitative PCR. These variations were not significant under the 0.15 threshold, as the fluorescence signal intensity on microarrays saturated at the lactating stage, thus minimizing the differences between stages. The significance threshold of 0.15 was the best compromise between the number of genes for the biological interpretation and the estimated error.

About $73 \%$ of these 2,330 probes gave a fluorescence signal $<10$ times the background signal; $2 \%$ were within $10 \%$ of the highest signal of the dataset, and $25 \%$ had intermediate signals. These genes fell into 19 clusters according to their expression profile (Fig. 2). It must be kept in mind here that the clustering was based on the contrasts of the estimated parameters, in other words on the difference between a given stage and the previous stage $\left(\theta_{\mathrm{i}}=\mu_{\mathrm{i}+1}-\mu_{\mathrm{i}}\right)$. As the distribution was not completely segregated, something that can occur with this clustering method, the lists of genes belonging to clusters with similar profiles were merged for IPA functional analysis into metaclusters, as follows: cluster 1 with clusters 9 and 12 (meta- 
Table 4. Identification of the IPA biological functions associated with differential analysis between two successive time points

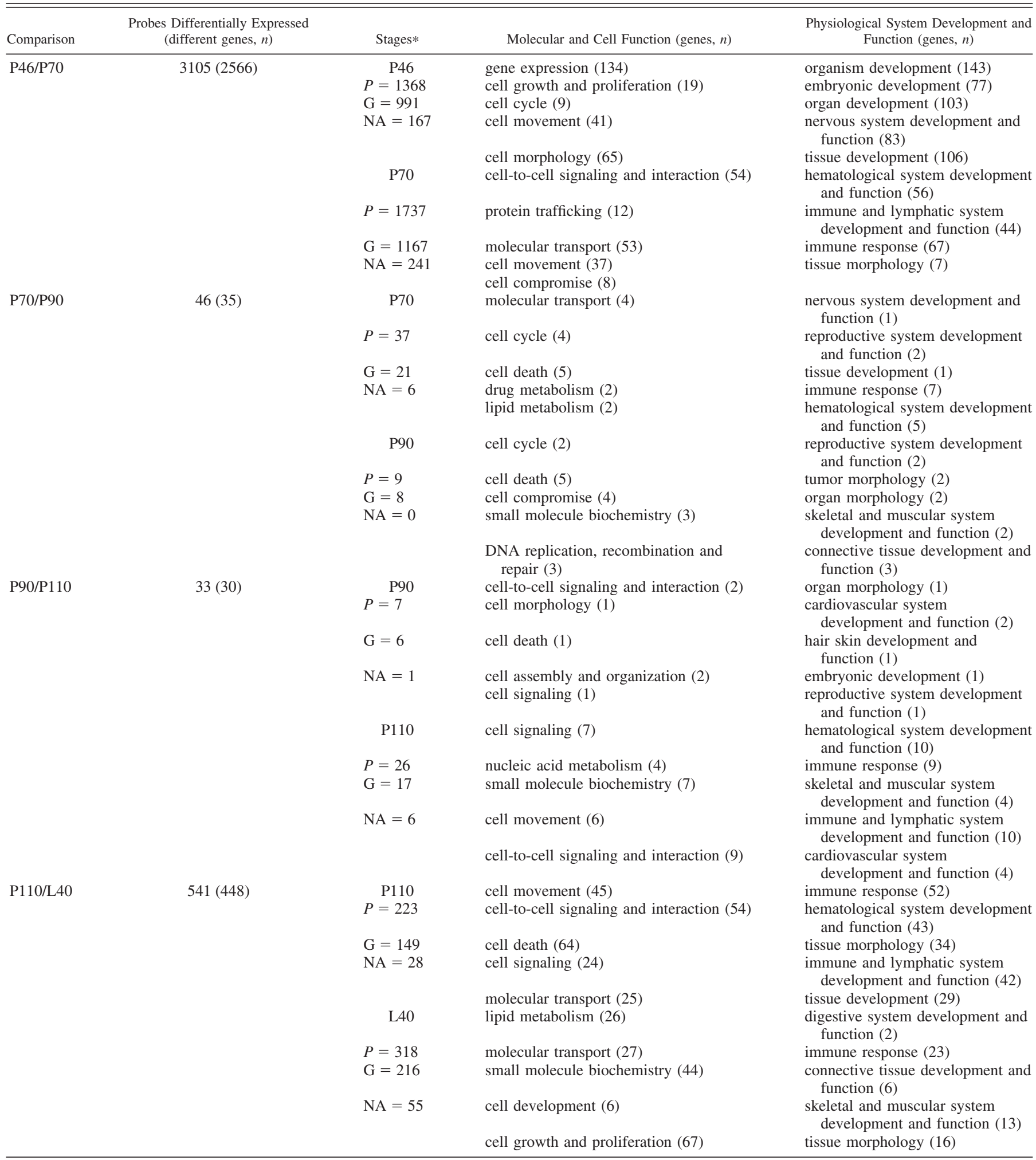

${ }^{*} \mathrm{P}$, number of probes; G, number of different genes with IPA annotation; NA, number of probes without IPA annotation. Probes contributing to expression data (fold change, signal intensities) in each comparison between successive time points are provided in supplemental data files Comparison_P46vsP70, Comparison_P70vsP90,Comparison_P90vsP110,CComparison_P110vsL40. 
Table 5. Top 25 upregulated and downregulated transcripts in goat mammary tissue at 40 days of lactation compared with 110 days of pregnancy (adjusted $P$ value $<0.05$ )

\begin{tabular}{|c|c|c|c|c|c|}
\hline Probe Number* & GenBank Accession & Gene Symbol & Encoded Protein & Log Ratio & Fold Change \\
\hline Bt00006833 & CK848760 & CSN1S1 & casein $\alpha$-s1 & 8.5 & 359.8 \\
\hline OLIGO_02149 & CN436503 & NCALD & neurocalcin $\Delta$ & 6.0 & 61.9 \\
\hline OLIGO_12034 & J05147 & $\angle A L B A$ & lactalbumin, $\alpha$ & 5.8 & 55.9 \\
\hline Bt00007030 & CK849125 & $\angle A L B A$ & lactalbumin, $\alpha$ & 5.7 & 52.2 \\
\hline OLIGO_12366 & EH125902 & CSN1S2A & casein alpha s2-like A & 5.5 & 46.8 \\
\hline Bt00006728 & CK848552 & $F A B P 3$ & fatty acid binding protein 3 & 5.2 & 36.4 \\
\hline Bt00007007 & CK849087 & BTN1A1 & butyrophilin, subfamily 1 , member A1 & 5.0 & 33.0 \\
\hline Bt00007059 & CK849167 & DNAJC12 & DnaJ (Hsp40) homolog, subfamily C, member 12 & 4.9 & 30.4 \\
\hline Bt00006984 & CK849042 & NUP107 & nucleoporin $107 \mathrm{kDa}$ & 4.9 & 29.6 \\
\hline Bt00002602 & CK773866 & NDUFB 8 & NADH dehydrogenase (ubiquinone) $1 \beta$-subcomplex, $8,19 \mathrm{kDa}$ & 4.8 & 28.8 \\
\hline Bt00007314 & CK849661 & $L P L$ & lipoprotein lipase & 4.8 & 27.4 \\
\hline Bt00007029 & NM_173959 & $S C D$ & stearoyl-CoA desaturase (delta-9-desaturase) & 4.8 & 26.9 \\
\hline OLIGO_11285 & NM_173959 & $S C D$ & stearoyl-CoA desaturase ( $\triangle$-9-desaturase) & 4.4 & 20.5 \\
\hline OLIGO_09278 & BF04 1126 & DNAJC12 & DnaJ (Hsp40) homolog, subfamily C, member 12 & 4.3 & 19.7 \\
\hline Bt00006966 & CK848999 & MED10 & mediator complex subunit 10 & 4.3 & 19.3 \\
\hline OLIGO_12148 & X81699 & SLC34A2 & solute carrier family 34 (sodium phosphate), member 2 & 4.2 & 19.0 \\
\hline Bt00004167 & CK776646 & PTPN11 & protein tyrosine phosphatase, nonreceptor type 11 & 4.2 & 18.6 \\
\hline Bt00007394 & CK849822 & NOP5/NOP58 & nucleolar protein NOP5/NOP58 & 4.2 & 18.5 \\
\hline \multicolumn{6}{|c|}{ Downregulated } \\
\hline OLIGO 11084 & CR452945 & COL1A1 & collagen, type I, $\alpha 1$ & -2.3 & -5.0 \\
\hline OLIGO_06802 & CN440096 & STMN1 & stathmin 1/oncoprotein 18 & -2.4 & -5.1 \\
\hline Bt00006868 & CK848824 & $C L U$ & clusterin & -2.4 & -5.3 \\
\hline Bt00007372 & CK849770 & STAT1 & signal transducer and activator of transcription $1,91 \mathrm{kDa}$ & -2.4 & -5.3 \\
\hline Bt00007230 & CK849494 & FCGR2A & Fc fragment of $\mathrm{IgG}$, low affinity IIa, receptor (CD32) & -2.4 & -5.5 \\
\hline Bt00007018 & CK849105 & BoLA-A & major histocompatibility complex, class I, A & -2.5 & -5.5 \\
\hline OLIGO_10329 & EH374936 & BoLA-A & major histocompatibility complex, class I, A & -3.0 & -7.8 \\
\hline OLIGO_05858 & CV798732 & GVIN1 & GTPase, very large interferon inducible 1 & -3.0 & -7.9 \\
\hline OLIGO_09615 & BM363744 & BoLA-A & major histocompatibility complex, class I, A & -3.0 & -7.9 \\
\hline OLIGO_05563 & BM362452 & CXCL9 & chemokine (C-X-C motif) ligand 9 & -3.0 & -8.1 \\
\hline OLIGO_12484 & CK955893 & CXCL10 & chemokine (C-X-C motif) ligand 10 & -3.1 & -8.8 \\
\hline Bt00007863 & CK949281 & $G B P 1$ & guanylate binding protein 1 & -3.2 & -9.4 \\
\hline OLIGO_10483 & CR452494 & COL1A2 & collagen, type I, $\alpha 2$ & -3.4 & -10.7 \\
\hline Bt00007938 & CK950779 & $U B D$ & ubiquitin D & -3.7 & -12.9 \\
\hline Bt00008202 & CK955893 & CXCL10 & chemokine (C-X-C motif) ligand 10 & -3.7 & -13.2 \\
\hline OLIGO_05270 & BF440277 & $U B D$ & ubiquitin D & -4.1 & -17.7 \\
\hline
\end{tabular}

*Number Btxxxxxxxx corresponds to Bovine Genome Oligoset V1.1 (Operon Biotechnologies); number OLIGO_xxxxx corresponds to NCBI GEO reference GPL2853.

cluster A); clusters 5 and 7 (metacluster B); clusters 6 and 8 (metacluster C); cluster 11 with clusters 14 and 16 (metacluster D); and clusters 13 and 15 (metacluster E). Biological functions determined by IPA software associated with each cluster or metacluster are shown in Table 6 (also see supplemental material). No precise descriptions are given for clusters 3 and 10 or for metacluster $C$, as the biological functions given by IPA were at the limit of significance, and genes belonging to these groups were not associated with a unique biological function.

Metacluster A (clusters 1, 9, and 12) comprised 218 genes showing an IDID expression profile in the "trajectory" nomenclature (I, increasing; D, decreasing; and F, flat) first proposed by Rudolph et al. (49) to describe the direction of statistically relevant changes between adjacent time points. The most relevant genes in these clusters were CXCL10, CXCR4 (che- 

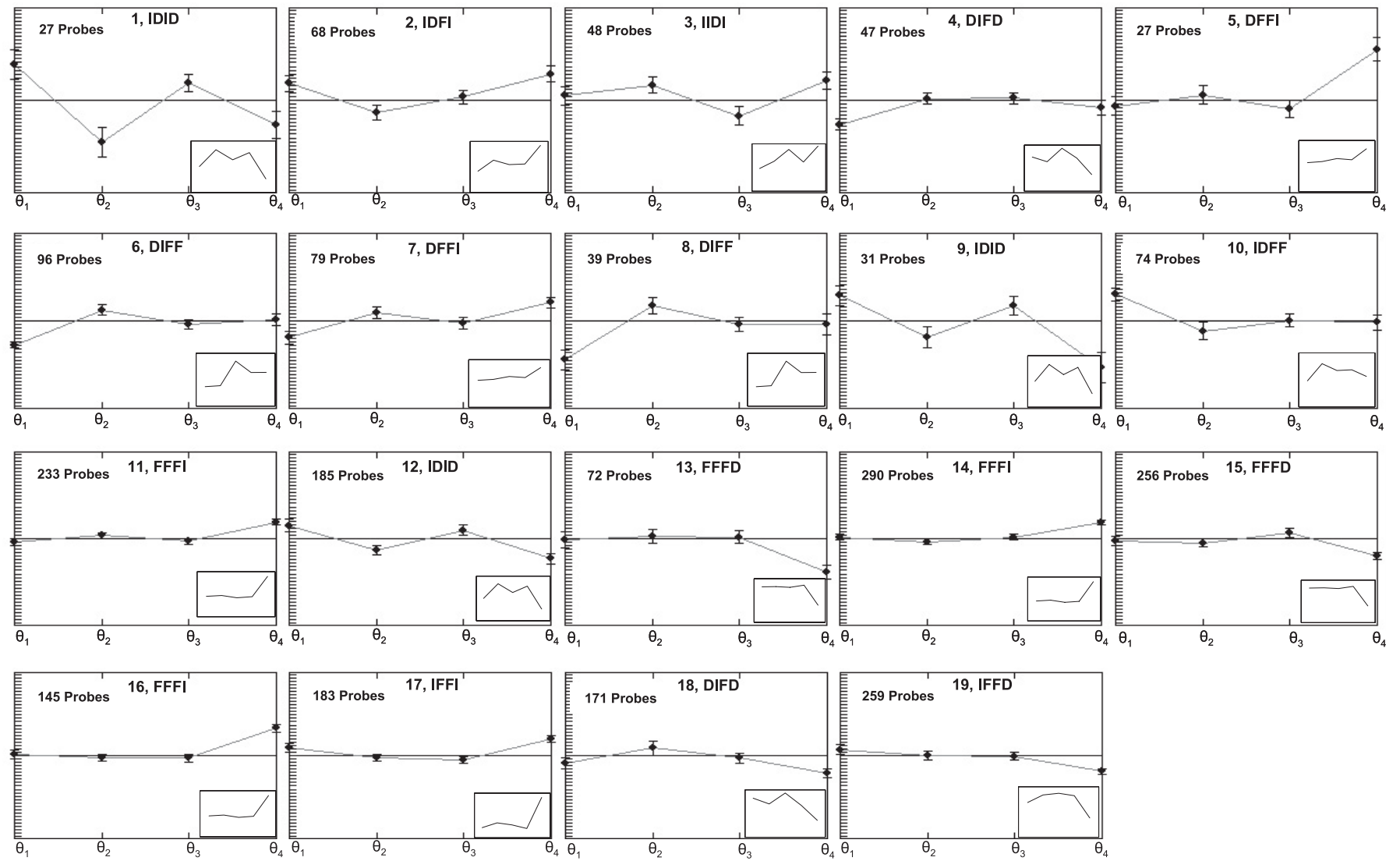

Fig. 2. K-means clustering allocating to 19 clusters the 2,330 probes equivalent to 1,696 genes that varied significantly at least once (in the corner box the gene expression profile drawn from the normalized signal intensity). I, increase; D, decrease; F, flat as proposed by Rudolph et al. (49); $\theta$, difference between one developmental stage and the previous stage. If $\theta$ is positive, the gene expression goes up, if $\theta$ is negative the gene expression goes down, and if $\theta$ is zero the gene expression does not vary.

mokine, C-X-C motif, receptor 4), IL18 (interleukin 18), IL2RG (interleukin 2 receptor, gamma), IRF8 (interferon regulatory factor 8), IFITM3 (interferon-induced transmembrane protein 3), a class of proteins mediating several cellular processes such as homotypic cell adhesion functions of interferons and cellular antiproliferative activities; IFNAR1 (interferon $\alpha$, $\beta$, and $\omega$ receptor 1), and BoLA-A and BoLA-DRB1, which encode bovine MHC proteins (class I and II, respectively). These genes were representative of immune and lymphatic system development and function. The IPA canonical pathways associated with the genes present in this metacluster were interferon signaling and antigen presentation pathways.

In cluster 2 there were 62 genes that showed an IDFI expression profile (Fig. 2). These genes included AP3S1 (adaptor-related protein complex 3, sigma 1 subunit), ERP29 (endoplasmic reticulum protein 29), RAB13 (member RAS oncogene family), SEC22B (vesicle trafficking protein homolog B), SLC36A1 (solute carrier family 36), which encode proteins that participate in molecular transport and protein trafficking.

Cluster 4 contained 43 genes displaying a DFFD expression profile. A representative gene of this cluster is adiponectin (ADIPOQ), which is mainly expressed in and secreted by adipose tissue.

Ninety-four genes belonged to metacluster B (clusters 5 and 7) displaying a DFFI expression profile. A significant proportion of the genes found in this metacluster $(n=44)$ are involved in lipid and nucleic acid metabolism, small molecule biochemistry, posttranslational modification, and cell death. One of the canonical pathways associated with these clusters is fatty acid biosynthesis, represented by genes encoding Fatty acid synthase (FASN) and acyl-CoA carboxylase (ACACA).

Clusters 11, 14, and 16 (metacluster D) comprised genes $(n=551)$ with an FFFI expression profile. A significant number of these genes are involved in cell death $(n=96)$ and lipid metabolism and secretion $(n=47)$. Genes participating in lipid metabolism and secretion are exemplified by ABCG2 (ATP-binding cassette, subfamily G, member 2), ACACA, LPL, SDC2 (syndecan 2), FABP2 (fatty acid binding protein 2), LPIN1 (lipin 1), AGPAT1 (1-acylglycerol-3-phosphate Oacyltransferase 1), ACADSB (acyl-Coenzyme A dehydrogenase, short/branched chain), ACSL1 (acyl-CoA synthetase long-chain family member 1), ALDH3B2 (aldehyde dehydrogenase 3 family, member B2), DPAGT1 (dolichyl-phosphate $\mathrm{N}$-acetylglucosaminephosphotransferase 1), and HDLBP (high density lipoprotein binding protein). Genes representative of cell death, such as Bcl-2, which has a well-known antiapoptotic function, and STAT3, shared the same expression pattern.

On the microarray there were three probes corresponding to ACACA. Two of them were directed towards two metaclusters ( $B$ and $D$ ), underlining the proximity between these two metaclusters. Surprisingly, the last one did not appear in any of the 


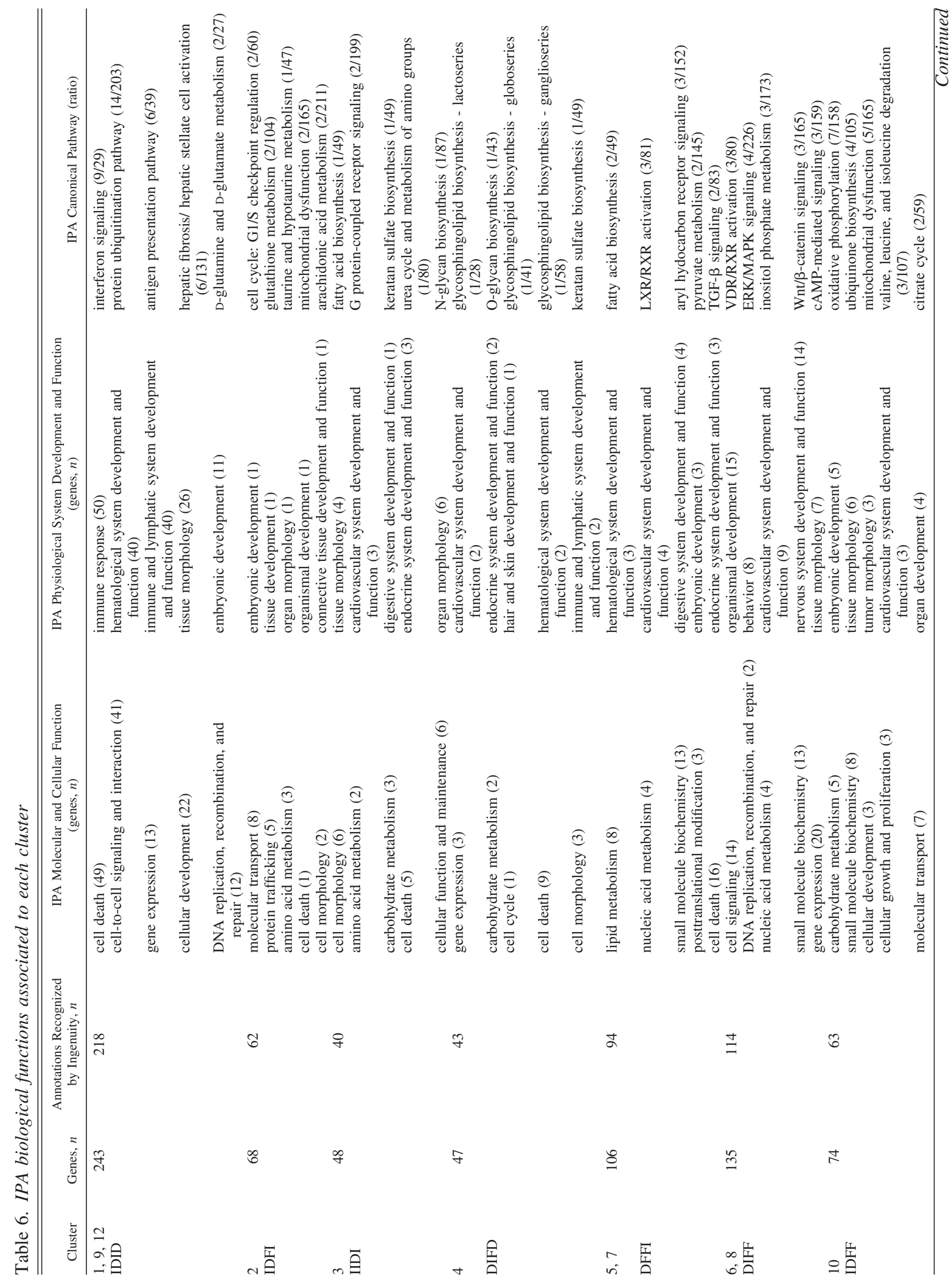




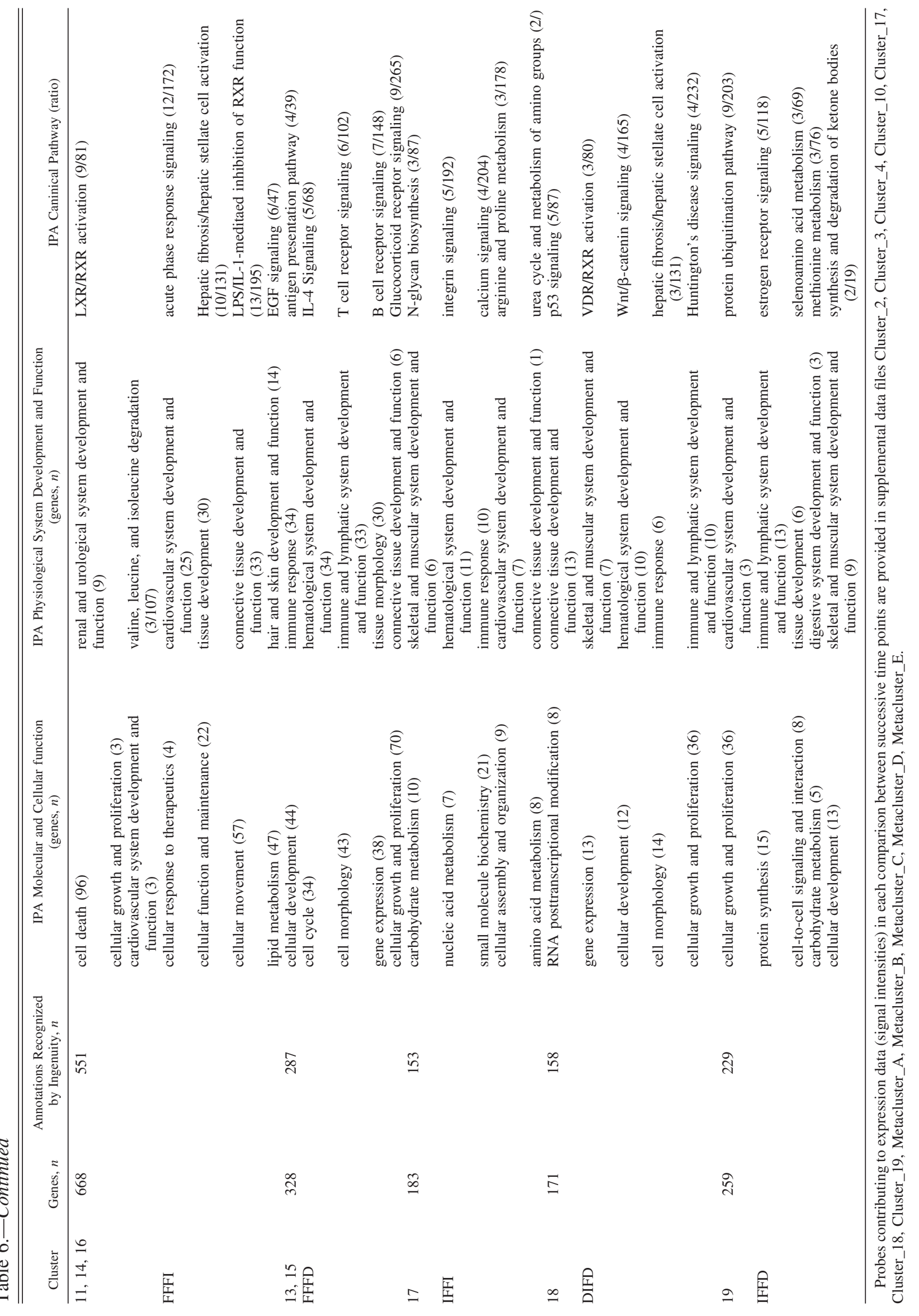


19 clusters. This was due to weak variability, very close to the threshold of significance.

Metacluster E (clusters 13 and 15) comprised 287 genes downregulated in lactation (FFFD). This metacluster is associated with the following biological functions: immune response and immune and lymphatic system development, which are allocated, at the molecular and cell level, to cell development, cell cycle, cell growth, and proliferation. Canonical pathways associated with this profile are antigen presentation pathways, IL-4 signaling, and T-cell and B-cell receptor signaling. Some representative genes are CD74, BoLA-A, BoLA$\mathrm{DMB}$, and BoLA-DRB1, which belong to the bovine MHC, IL2RG, and IL4R (interleukin 4 receptor), which are interleukin receptors, and NFATC2 (nuclear factor of activated Tcells, cytoplasmic, calcineurin-dependent 2 ), which is a positive regulator of transcription.

Cluster 17 contained 153 genes with an IFFI expression pattern. These genes included UGP2 (UDP-glucose pyrophosphorylase) and B4GALT1 (UDP-Gal:betaGlcNAc beta 1,4galactosyltransferase, polypeptide 1), which contribute to carbohydrate metabolism, including lactose synthesis. This cluster also contained genes encoding milk proteins such as $\alpha_{\mathrm{s} 1}$-casein (CSN1S1) and $\beta$-casein (CSN2), confirming that many of the genes involved in milk synthesis and secretion are transcribed before the onset of lactation.

Cluster 18 contained 158 genes with a DIFD expression profile and mainly involved in RNA posttranscriptional modification and gene expression. This cluster included genes coding for splicing proteins such as SF3B3 (splicing factor 3b, subunit 3), SFRS4 (splicing factor, arginine/serine-rich 4), SFRS7 (splicing factor, arginine/serine-rich 7), SFRS12 (splicing factor, arginine/serine-rich 12), SFRS (splicing factor, arginine/serine-rich), and also DNA replication or transcription factors such as HMGB1, MED1 (mediator complex subunit 1), SSRP1 (structure specific recognition protein 1), and WT1 (Wilms tumor 1).

Finally, cluster 19 grouped together 229 genes with an IFFD expression profile. These genes were representative of cell growth and proliferation and protein synthesis. Genes in this cluster contribute to several biological functions. One encodes the local factor $\mathrm{C} / \mathrm{EBP} \beta$, which is involved in the cell fate decision leading to progesterone receptor expression and then affects cell proliferation through a paracrine mechanism (22).

Validation of microarray results by $q P C R$. Some results of the microarray analysis were validated by qPCR applied to the same mammary tissue samples. In addition, as some specific genes that were expected to be differentially expressed (involved in milk protein biosynthesis, milk fat globule biogenesis, or mammary tissue development) were not correctly analyzed by the microarray approach (signal saturation for several probes), their expression profiles were specifically analyzed by qPCR and then compared with the microarray results. A set of 19 PCR systems was designed to analyze the expression of genes involved in biosynthesis and secretion of lipids (DGAT1, SCD, FASN, ADRP, FABP4, MFGE8, BTN1A1) and milk proteins (CSN1S1, CSN1S2, CSN2, CSN3, LALBA, LTF, LPO), and mammary tissue development (BMP-7, ID-2, OPN), as well as ubiquitous genes (JDP-1, CSNK2A2). In addition, four genes relevant to mammary function but absent from the probe repertoire on microarrays (KRT14, GLYCAM1, BLG, Elf5) and four genes representative of two main clustering expression profiles (CXCL9, ABCG2, IGFBP5, LPIN1) were also analyzed.

The microarray and qPCR expression profiles were compatible for most of the genes investigated, with a global correlation coefficient close to 0.82 (Figs. 3 and 4). Genes with discrepant results between qPCR and the microarray approach included DGAT1, CSN1S2, CSN2 and CSN3 (Fig. 3). DGAT1 (Fig. 3A) gave weak signal intensity at every stage. As the DGAT1 mRNA sequence is incomplete for Capra hircus and Ovis aries, we compared the nucleotide sequence of the DGAT1 oligonucleotide probe printed on the microarray with the DGAT1 mRNA sequence of Bos taurus (NCBI: NM_174693), Homo sapiens (NCBI: NM_012079), Mus musculus (NCBI: NM_010046), Sus scrofa (NCBI: AY093657), and Bubalus bubalis (NCBI: DQ886485). The number of mismatches was respectively $0,30,30,19$, and 4 . This region seems highly variable across species, suggesting the potential occurrence of mismatches between the probe spotted on the microarray ( $B$. taurus sequence) and the $C$. hircus mRNA sequence, possibly explaining the weak signal intensity and the absence of differences between developmental stages in the microarray method. For most of the genes encoding major milk proteins (Fig. 3B), changes between stages, for instance between L40 and P70, were higher with qPCR than with microarray analysis. This is probably due to saturation of the fluorescence signal on the microarrays, leading to an underestimation of the differences.

Regarding lipid biosynthesis and secretion, two types of gene expression profile were observed (Fig. 3A). The first corresponds to genes generally strongly expressed during lactation (BTN1A1, SCD, MFGE-8) and the second to genes more or less expressed at every stage of pregnancy (FASN, ADRP, FABP4) and upregulated during lactation. Milk protein genes could be divided into three classes according to their expression profiles (Fig. 3B), including: 1) genes that are expressed at mid-pregnancy and that are highly expressed during lactation (CSN2, CSN1S2, CSN3 and LALBA); 2) genes that are highly expressed only during lactation (CSN1S1 and LPO); and 3) genes that are highly expressed at midpregnancy and weakly expressed during lactation (OPN and LTF). Genes known for their involvement in mammary tissue development (BMP-7 and ID-2) were expressed at every developmental stage (Fig. 3C), and CSNK2A2 displayed the same pattern of expression.

To validate expression profiles obtained by clustering, key genes belonging to trajectory metaclusters $D$ and $A$ were selected and analyzed. LPIN1, ABCG2 and IGFBP5 (metacluster $D$ ) showed, as expected, drastic upregulation during lactation. Likewise, CXCL9 which follows the same profile as genes in metacluster $A$ (not included in this metacluster because of borderline statistical significance, but functionally interesting) was confirmed as being upregulated at P70 and P110 (Fig. 4).

Finally, among the key genes of interest absent from the microarray (Fig. 5), JDP-1, BLG, and GLYCAM1 showed high expression during lactation, whereas Elf5 also displayed significant expression at P70. In contrast, KRT14 was equally expressed at every developmental stage, suggesting that myoepithelial cells are present very early in pregnancy and that their numbers change little during pregnancy and the transition to lactation. This is not really surprising, as these cells are 
A
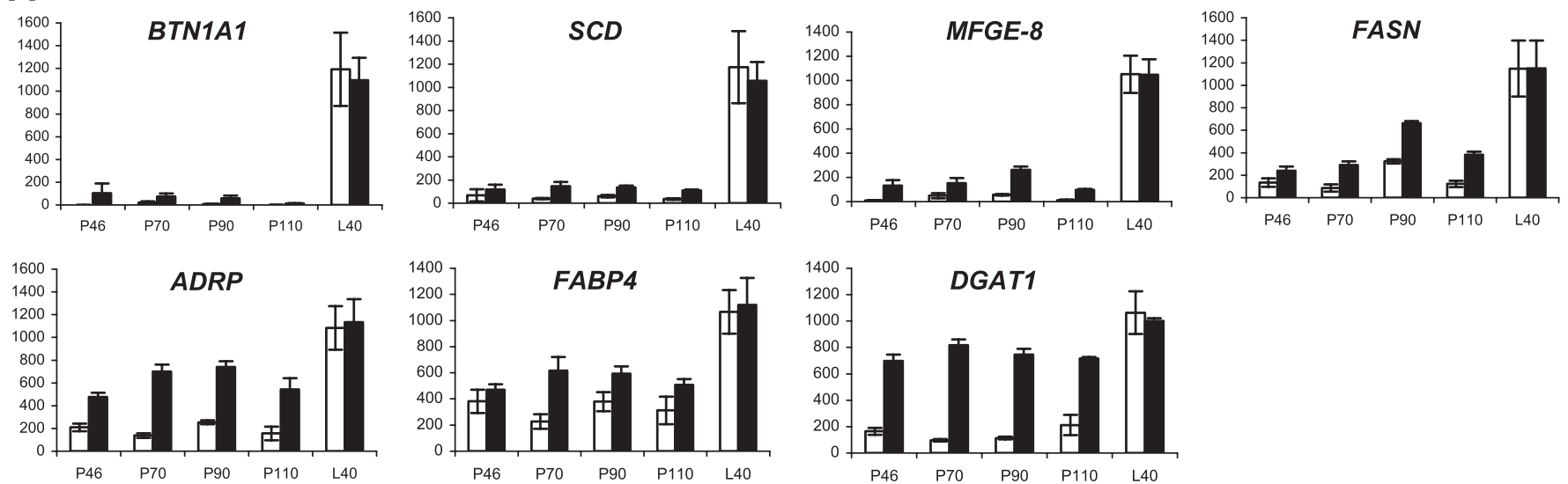

B
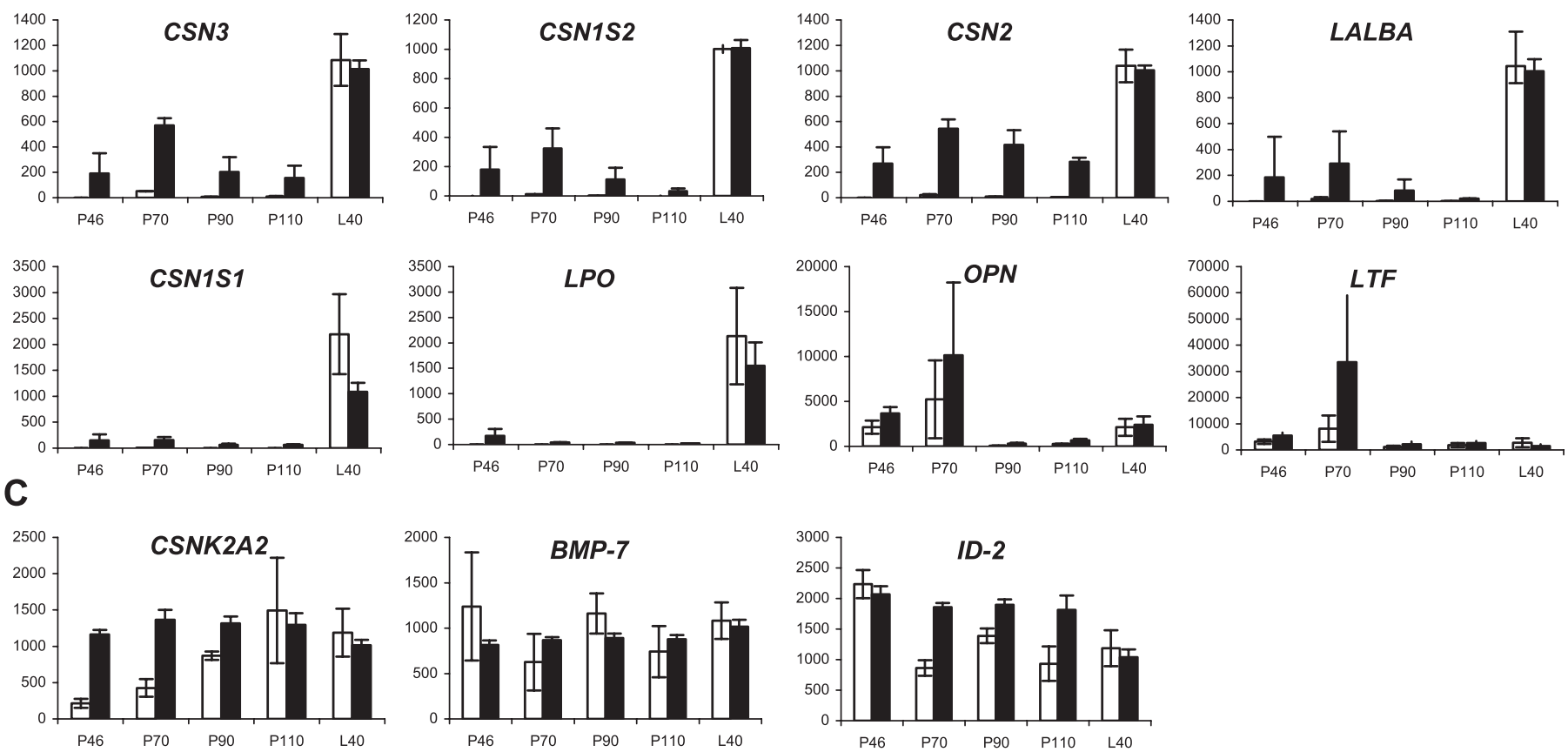

Fig. 3. Gene expression profiles obtained by qPCR and microarray analysis. $A$ : lipid biosynthesis genes; $B$ : milk protein genes; $C$ : mammary setting and ubiquitous genes. BTN1A1, butyrophillin; SCD, stearoyl CoA desaturase; MFGE-8, milk fat globule-EGF factor 8; FASN, fatty acid synthase; ADFP, adipophillin; FABP4, fatty acid binding protein 4; DGAT1, diacylglycerol acytransferase 1; CSN3, casein к; CSN1S2, casein $\alpha_{\mathrm{S} 2}$; CSN2, casein $\beta$; LALBA, $\alpha$-lactalbumin; CSN1S1, casein $\alpha_{\mathrm{S} 1}$; LPO, lactoperoxydase; OPN, oesteopontin; LTF, lactoferrin; CSNK2A2, casein kinase 2; BMP-7, bone morphogenetic protein 7; ID-2, inhibitor of DNA binding 2. White (qPCR) and black (microarray) bars represent the relative abundance of target transcripts at the different stages of pregnancy, determined assuming the expression of individual lactation was 1,000.

known to aid in milk ejection and also to regulate ductal morphogenesis in mice during pregnancy (40).

Morphological differentiation of the goat mammary gland during pregnancy and lactation. During pregnancy the mammary gland undergoes profound structural reorganization, with the formation of secondary branches and extensive lobuloalveolar development, primarily driven by progesterone. This phase of differentiation results in a sharp increase in the number of luminal epithelial cells (MEC). As previously reported (24), in ruminants, the ducts and lobular units are separated from adipocytes by multiple layers of fibroblastic connective tissue. Histological changes in goat mammary gland morphology during pregnancy and lactation are shown in Fig. 6. Unfortunately, owing to the small amount of mammary tissue available at P46, we could not perform any morpholog- ical studies at this stage, all the material sampled being used for gene expression profiling. At midpregnancy (P70), the ratio between the area occupied by MEC (pink-brown area in Fig. $6 A$ ) and stromal tissue was $\sim 30 \%$. At P90 (Fig. 6C), the area of LAS increased in the stromal parenchyma. Later in pregnancy (P110, Fig. 6E), inter- and intralobular stromal tissues regressed to an average of $<10 \%$ during lactation (L40, Fig. $6 G$ ), even though development was sometimes heterogeneous across different sections. While it is quite easy to identify LAS and alveolar epithelial cells, it is difficult to distinguish other cell types in this abundant connective tissue without using specific immunohistological approaches.

As shown in Fig. 6B, at higher magnification the alveoli in midpregnancy (P70) are completely or partially filled with MEC. At P90 the alveolar lumen is more open and MEC are 

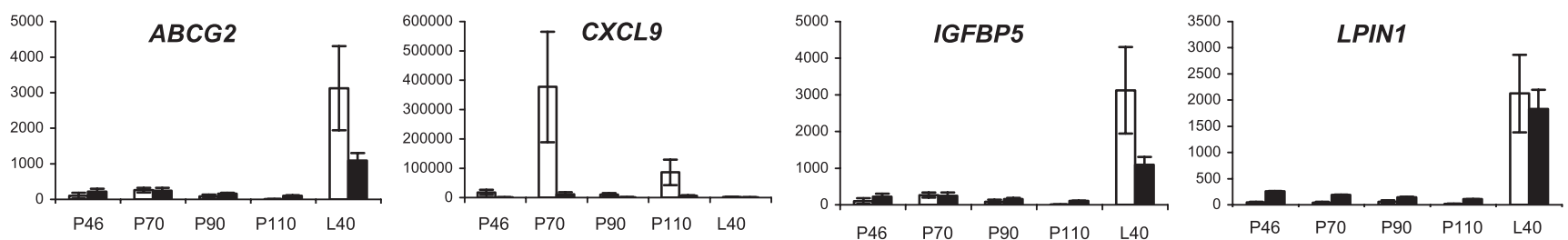

Fig. 4. Gene expression profiles obtained by qPCR and microarray analysis of genes representative of expression profiles corresponding to metaclusters $A$ and D. ABCG2, ATP-binding cassette subfamily G (white), member 2; CXCL9, chemokine (C-X-C motif) ligand 9; IGFBP5, insulin-like growth factor binding protein 5; LPIN1, lipin 1. White (qPCR) and black (microarray) bars represent the relative abundance (determined assuming the expression of individual lactation was 1,000$)$ of target transcripts at the different stages of pregnancy.

organized in one or two layers (Fig. 6D). At P110, MEC organization strongly resembles a monolayer (Fig. 6F) and, within the expanding luminal space, the presence of secretory material very similar to milk, with lipid droplets (white spots), can be observed, pressing the epithelial cells against the alveolar wall. During lactation (Fig. $6 H$ ), we distinguished MEC monolayers within alveoli. The lumen was very thin and empty, as the goats were milked before slaughter.

\section{DISCUSSION}

This is the first global gene expression study designed to follow changes in ruminant mammary gland ontogeny during pregnancy. We chose to study goats, as they are smaller and cheaper than cattle. As pregnancy lasts $\sim 150$ days in goats, P46 represents the end of the first third of pregnancy and P70 the end of the first half.

Three findings with respect to goat mammary gland terminal differentiation are particularly noteworthy. First, the first half of pregnancy was characterized by downregulation of genes usually expressed in adipocytes, whereas genes whose expression is usually considered representative of a differentiated mammary epithelium, such as genes coding for immune function and milk proteins, were already expressed. Second, a switch occurred between late pregnancy (P110) and established lactation characterized by downregulation of genes associated with immune functions, whereas genes coding for lipids and lactose biosynthesis and secretion were strongly upregulated.
The third important result is the upregulation of genes encoding proteins involved in both innate and specific immunity at midpregnancy (P70) and at the beginning of the last third of pregnancy (P110).

Changes in cell composition during the first half of pregnancy. Histological changes occurring in the goat mammary gland during the first half of pregnancy (Fig. 6) were consistent with gene expression data (see thereafter) and confirm that the functional differentiation process of goat mammary gland is similar to that previously reported for mice (4). Between P46 and P70, a fall was noted in the ratio of interlobular stromal tissue (mainly composed of adipocytes and fibroblasts in ruminants) to secretory tissue (primarily composed of epithelial and myoepithelial cells). This decrease follows a reduction in the expression of adipocyte markers such as adiponectin (26) (belonging to cluster 4) and PPAR $\gamma$ (32), FGF-10 (43) and fibroblast markers such as S100A4 and vimentin (VIM).

In addition, genes involved in mice lobulo-alveolar development and differentiation (4), such as VEGF and sterol regulatory element binding transcription factor 1 (SREBF1), were downregulated, while Elf5 and cyclin D1 (CCND1) were upregulated between P46 and P70, suggesting that differentiation of goat mammary tissue follows the same pattern as that of mice mammary tissue. ID2, which is required for lobuloalveolar development (36), is significantly expressed during pregnancy in goat mammary tissue. In mice, the switch be-
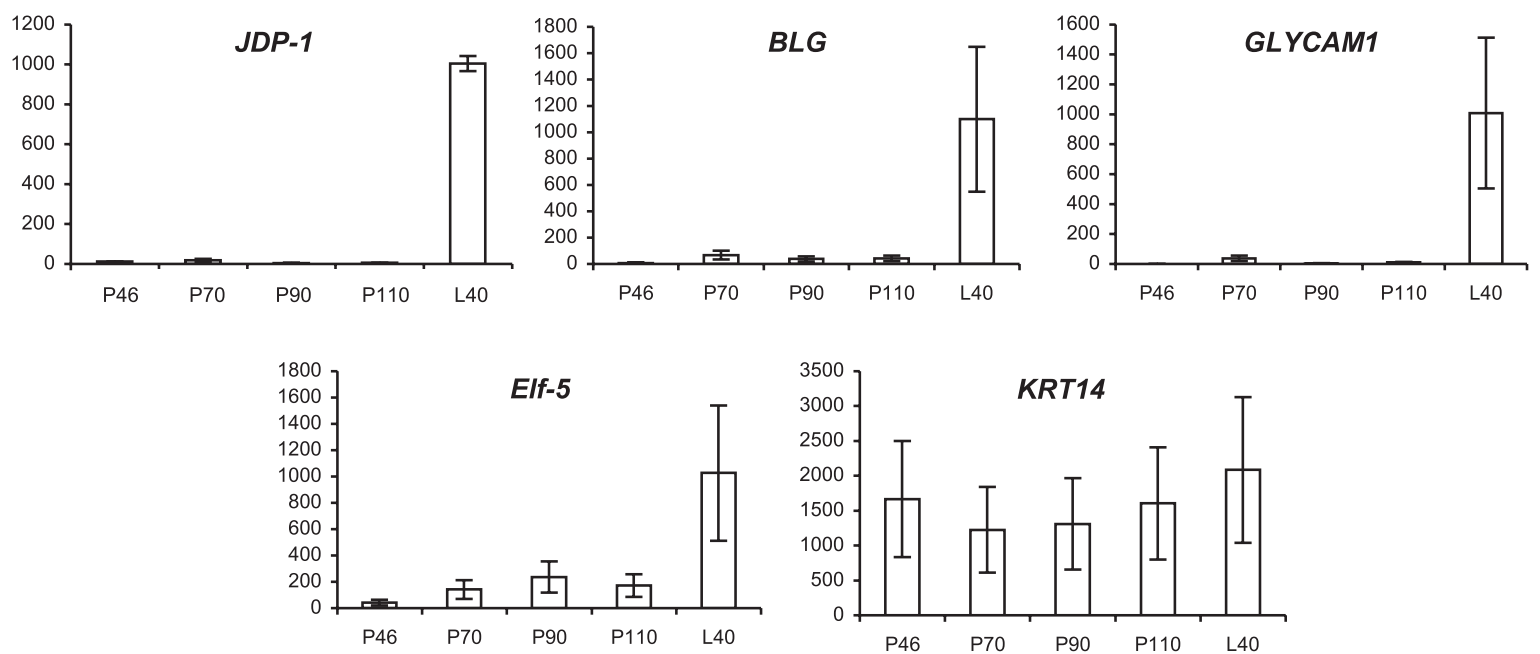

Fig. 5. Gene expression profiles obtained by qPCR of genes relevant to mammary function and absent from the repertoire printed on microarrays. BLG, $\beta$-lactoglobulin; GLYCAM1, glycosylation dependent cell adhesion molecule 1; Elf-5, E74-like factor 5; KRT14, keratin 14. White bars represent the relative abundance of target transcripts at the different stages of pregnancy, determined assuming the expression of individual lactation was 1,000 . 

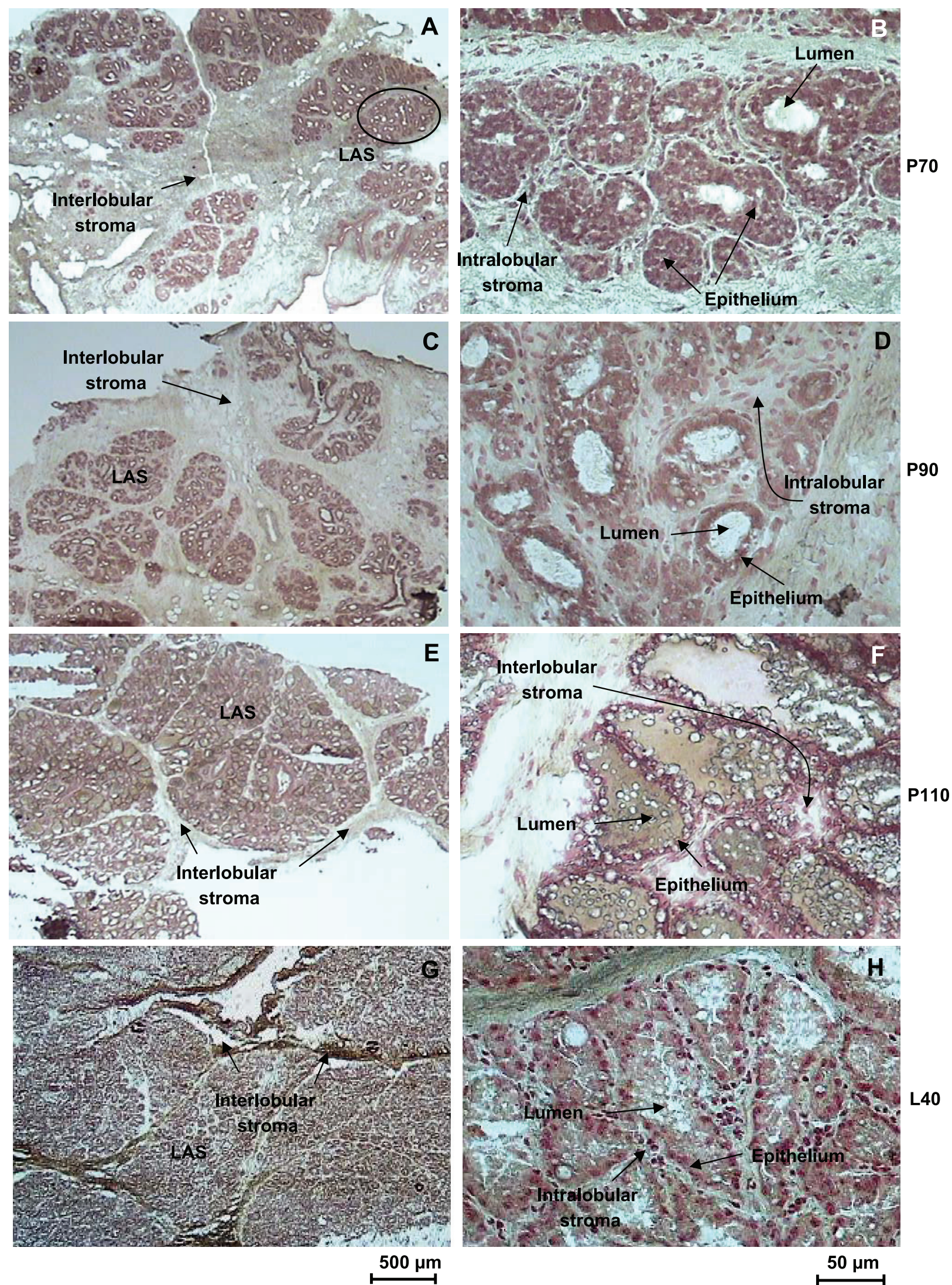

Fig. 6. Histological sections of goat mammary tissue during pregnancy and lactation. Mammary glands were taken from goats on day 70 (P70, $A$ and $B$ ), day 90 (P90, $C$ and $D$ ), and day $110(\mathrm{P} 110, E$ and $F$ ) of pregnancy and on day 40 (L40, $G$ and $H$ ) of lactation, then frozen in liquid nitrogen, sectioned, and stained with hematoxylin. On the left micrographs $(A, C, E$, and $G)$ the scale bars represent $500 \mu \mathrm{m}$, whereas those on the right $(B, D, F$, and $H)$ represent $50 \mu \mathrm{m}$. LAS, lobuloalveolar structure. 
tween the first third and midpregnancy is characterized by lobulo-alveolar development accompanied by cell proliferation $(4,23,44,47)$.

Therefore, our results suggest that, between P46 and P70, the goat mammary gland changes from a stromal tissue composed of adipocytes and fibroblasts to an organized lobuloalveolar tissue with an epithelium internally coating alveoli in which milk will be synthesized and secreted after parturition. This is compatible with histological observations (Fig. 6) and morphological findings obtained in 1979 by Swanson and Poffenbarger (59), who found that bovine mammary tissue already has alveolar structures at midpregnancy ( $5 \mathrm{mo}$ in their study). This reminds us that the gene expression data derived from this comparison must be interpreted with care, as, during the first half of pregnancy, the mammary gland, which is a complex organ composed of different cell types, undergoes marked structural modifications and profound changes in the proportion of the different cell types. By adjusting gene expression values to changes in the size of cell type-specific compartments, Wang et al. (62) show that it is possible to increase both the sensitivity and the specificity of differential gene expression analyses and to assess variations in gene expression due to intrinsic intracellular regulation rather than shifts in the relative cell type abundance (62). However, this "deconvolution strategy" requires either precise characterization of the two major cellular compartments (epithelial and stromal, themselves composed of different cell types) or the use of homogeneous cell populations to derive specific panels of transcripts. Such an approach could not be applied to the goat model.

Epithelial differentiation and activation of secretion. The array data revealed that genes encoding $\mathrm{\kappa}$-casein and, to a lesser extent, $\alpha_{\mathrm{s} 2^{-}}$and $\beta$-caseins, $\alpha$-lactalbumin, and $\beta$-lactoglobulin are already expressed at midpregnancy in goat mammary tissue. Moreover, Elf5, a member of the Ets transcription factor family (epithelium-specific subclass) that regulates a number of epithelium-specific genes found in tissues containing glandular epithelium, was also expressed at midpregnancy. In mouse mammary tissue, milk protein synthesis is regulated by two transcription factors: Stat5 and Elf5 (4). The presence of Elf5 and milk protein transcripts in goat mammary tissue at midpregnancy complies with the theory developed for mouse mammary tissue according to which, at midpregnancy, there are sufficient differentiated MEC to express markers of milk synthesis (47). Milk protein genes are weakly expressed in goat mammary tissue during pregnancy, as also previously shown in mice, using an immunohistochemical approach (27). Semiquantitative Western blot analysis of $\alpha_{\mathrm{s} 1^{-}}$and $\beta$-caseins in epithelial cell fractions from mouse mammary gland showed that intraepithelial caseins are present at trace levels during the initial stages of pregnancy (between days 0 and 4), decline to even lower levels during midpregnancy (days 6 to 8 ), and then rise to high levels during the last third of pregnancy (day 14). At the messenger level, based on our qPCR data, we noted a trend toward a slight increase in the expression of caseinencoding genes at midpregnancy, especially CSN3 ( $\kappa$-casein). However, casein synthesis can be substantially regulated at the level of translation (15). In both goat and mice, the expression of milk protein genes remains very limited during pregnancy compared with the burst occurring at the onset of lactation ( $>1,000$-fold, based on qPCR results), when the mammary gland is completely differentiated and produces huge amounts of milk. The fold change obtained with the microarray technology was more limited (359-fold), with $\alpha_{\mathrm{s} 1}$-casein transcripts between P110 and L40. This result is not in complete agreement with the microarray results obtained by Finucane et al. (20) for bovine mammary gland at the onset of lactation, using the Affymetrix Genechip Bovine Genome Arrays (23,000 gene probes). These authors report that none of the milk protein genes showed significant changes in expression from late pregnancy (5 days before parturition) to early lactation (10 days after parturition). This discrepancy is probably due, at least in part, to the larger interval between the last stage of pregnancy taken into account in our study (P110, 40 days before parturition), compared with 5 days in the Finucane study. However, in mice, the expression of milk protein genes increases gradually during pregnancy, especially in the last part of pregnancy, and there is no sharp increase at secretory activation (parturition), except for $\delta$-casein, $\alpha$-lactalbumin, and the major milk mucin MUC1 (4).

In the pregnant goat mammary gland, milk protein genes were not the only highly expressed genes. Genes involved in lipid biosynthesis and secretion were also significantly expressed. Indeed, microarray analysis showed that adipophilin (ADRP), acyl CoA:diacylglycerol transferase 1 (DGAT1), fatty acid binding protein 4 (FABP4), and fatty acid synthase (FASN) are expressed throughout pregnancy. This result, which was confirmed and validated by $\mathrm{qPCR}$, is not really surprising, as fatty acid synthase activity has been already measured in the mammary gland of pregnant cows (34) and rabbits (33) and as ADRP mRNA is also found in pregnant mouse mammary gland (4). This is consistent with the fact that, during pregnancy, cell proliferation requires the synthesis of many membranous lipids composed of long-chain fatty acids (as reviewed by Ref. 34) and also with the presence of a significant proportion of adipocytes in the early stages of pregnancy. Thus, the lipid synthesis activity observed in goat mammary gland during pregnancy would not be dedicated to milk synthesis and secretion but rather to the cell proliferation associated with mammary gland development, which requires membrane biosynthesis. The expression of DGAT1 during pregnancy contributes to epithelial proliferation and alveolar development of mammary tissue. This finding is in agreement with results showing that mice lacking the triglyceride synthesis enzyme (DGAT1) have impaired mammary gland development characterized by decreased epithelial proliferation and alveolar development and reduced expression of markers of functional differentiation (13).

Nevertheless, genes involved in milk lipid biosynthesis such as LPL, the long chain acylCoA synthetase homolog 1 (ACSL1) and lipin1 (LPIN1), as well as in lactose synthesis, such as UGP2 and B4GALT1 (metacluster D and cluster 17), were sharply upregulated in the goat mammary gland after parturition (Table 5). Likewise, Akt1, a serine/threonine protein kinase with a key role in the regulation of glucose transport and lipid metabolism $(4,53)$ was significantly upregulated between P110 and L40 (metacluster D). Butyrophilin (BTN1A1), which is thought to be an activator of milk secretion (41), followed the same pattern (Table 5 and Fig. 3A). SREBF1, which is a central node in the milk lipid metabolism network and controls the transcription of most of the genes that regulate milk fat synthesis in mice (49) and cattle (9), is also a 
critical regulator of transcription in goat, as many genes regulated by this factor (ACACA, FASN, LPL, ACSL1, and INSIG1) and showing the same expression pattern (FFFI), were identified in our study.

In addition, the gene encoding $\alpha_{\mathrm{s} 1}$-casein (CSN1S1), the expression profile of which was somewhat different from that of other casein transcripts, as confirmed by qPCR (Fig. 3, pattern $B$ ), seems to be significantly expressed only during lactation. This observation is consistent with the notion that $\alpha_{\mathrm{s} 1}$-casein could be necessary for casein secretion in goat mammary tissue (14).

At the transition from pregnancy to lactation, our study and that of Finucane et al. (20) identified only three common genes among the top 50 differentially expressed genes, namely those encoding lactoperoxidase (LPO), lipoprotein lipase (LPL), and lipin 1 (LPIN1). As Finucane et al. compared the time points 5 days before and 10 days after parturition, while we compared time points 40 days before and after parturition, the expression of LPO, LPL and LPIN1 would appear to be sharply increased ( 20-fold for LPO and LPL) after parturition. On the other hand, transcript levels of genes (CSN1S1, CSN1S2, LALBA, BTN1A1, FABP3, SCD) that were upregulated only during lactation in our study are likely to have increased gradually until parturition, based on our $\mathrm{APCR}$ results and on previous studies of mouse mammary tissue $(4,49,50)$.

General biological functions associated with lactating mammary gland validate the conclusion, supported by our study, that the lactating stage is characterized by molecular transport, cell movement and protein trafficking. Thus, activation of secretion seems to occur only after parturition in the mammary gland of ruminants, including cows (20), and also in mice (4).

Expression of genes of immunity during pregnancy marks tissue remodeling and differentiation. We observed the expression of immune cell signaling genes in the mammary gland of pregnant nulliparous goats. Most of the genes with an IDID expression profile (increased expression at midpregnancy and at 110 days of pregnancy) code for proteins involved in innate and specific immunity.

Genes of innate immunity code for proteins of the complement system (C1QB, CD2, CD3E, CD69, CD84, CD96), interferons, interferon regulatory factors and receptors (IRF1, IRF2, IRF8, IFNAR1), interleukins and interleukin receptors (IL18, IL2RG), chemokines and chemokine receptors (CCL5, CXCL10, CXCR4), and receptors of natural killer cells (KLRK1) or macrophages (MSR1). We also noted the expression of genes coding for receptors involved in the innate response activation to viral infection (TLR3), or protein effectors of innate immunity such as lactoferrin and lysosomal proteases (cathepsins $\mathrm{C}$ and $\mathrm{S}$ ). Genes of specific immunity were mainly genes coding for immunoglobulin receptors with high affinity for the Fc portion of IgG (FCGR3A) or IgE (FCER1G), or for bovine MHC (BoLA-A, BoLA-DMB, BoLA-DRB1). There were also effectors of the immune response, with the expression of genes encoding proteins of the multicatalytic proteinase complex immunoproteasome (PSMB8, PSME1, PSME2). Interaction networks between these genes that share the same expression profile (metacluster A), using IPA for enrichment, in gene sets related to molecular and cell functions (Fig. 7), suggest a central role for IRF1 and IRF2 and for signal transducers and activators of transcription 1 and 2 (STAT1 and STAT2). These two transcription factors are able to form heterodimers that can bind the interferon-stimulated response element and thereby increase the expression of interferon-stimulated genes.

Several of the proteins mentioned above are chemoattractants or activators of blood monocytes, memory $\mathrm{T}$ helper cells, and/or eosinophils. Indeed, IL18 acts on natural killer cell activity, lymphocyte $\mathrm{T}$ helper 1 (Th1) interferon gamma (IFN- $\gamma$ ) production and Th1 cell proliferation (reviewed in ref 58). CCL5 is a chemoattractant for blood monocytes, memory $\mathrm{T}$ helper cells and eosinophils (45). When it binds to CXCR3, CXCL10 stimulates monocyte, natural killer cell and T-cell migration (48).

The expression of monocyte attractants in pregnant goat mammary gland suggests that macrophages and eosinophils migrate from blood to mammary tissue. This phenomenon has been already reported during mouse mammary gland development and was associated with matrix remodeling (reviewed in Ref. 21). Thus, goat mammary gland differentiation could comprise two phases of tissue remodeling, one at midpregnancy and one in the last third of pregnancy (P70 and P110), characterized by phagocytosis of one cell type (adipocytes) or stroma and development and differentiation of another cell type (epithelium). This is in line with the upregulation of genes coding for proteins involved in the ruminant mammary gland immune response to mastitis, exemplified by $\mathrm{C} 1 \mathrm{q}$ and lactoferrin. C1q plays an essential role in the classical pathway of the complement system (46), whereas lactoferrin has been reported to be mainly expressed by the MEC lining the ducts and the cistern (35) and to function as a iron captor preventing bacterial development $(46,54)$. Other proteins are specific to epithelial cells, such as TLR3, which is mainly described in intestinal epithelial cells of normal mucosa (12).

The notion by which the goat mammary gland expresses a large number of innate immune genes in pregnancy is consistent with the idea developed by Vorbach et al. (61) that mammary glands originate in the innate immune system. The innate immune system, also known as nonspecific or nonimmune responsiveness, is a first line of immediate defense. This type of protection appears crucial for a tissue exposed to multiple etiological agents.

Moreover, cluster analysis of lactating goat mammary gland showed downregulation of the IL-4 signaling pathway (metacluster E), characterized by downregulation of the IL4R and NFATc 2 genes. Proteins encoded by these genes are lymphocyte $\mathrm{T}$ helper 2 (Th2) cytokines that participate in mouse mammary gland development in vivo (30). Secretion of these cytokines by mouse MEC signals the induction of the differentiation process (30), and shows the role of immune cell signaling proteins in MEC fate and function (63). At 46 days of pregnancy, the goat mammary gland expresses genes of the IL-4 signaling pathway, suggesting that the differentiation process is already engaged at this stage. The decreased expression of genes encoding these proteins during lactation is consistent with the notion that the 40th days of lactation corresponds to a stage at which MEC are fully differentiated and the mammary gland does not express differentiation markers.

Taken together, these data show the increased expression in the goat mammary gland at midpregnancy of a large number of genes encoding proteins involved in the immune system, as well as milk proteins. A common regulatory pathway (or at least pathways mobilizing common effectors) 


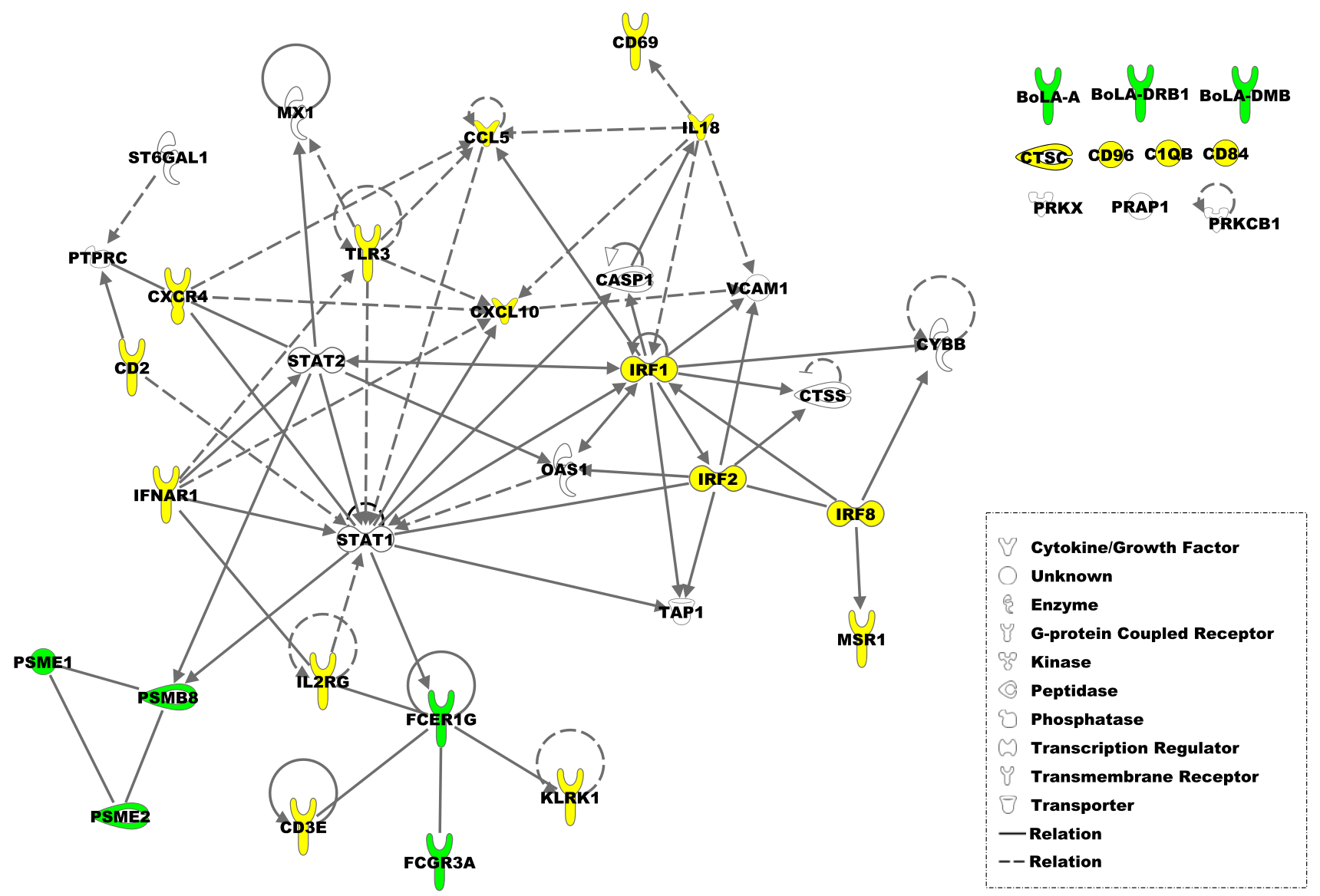

Fig. 7. Interaction networks between immune response genes with IDID expression profiles (metacluster A). Genes of the innate immune response are in yellow. Genes of the specific immune response are in green. BoLA-A: major histocompatibility complex, class I, A; BoLA-DMB: major histocompatibility complex, class II, DM $\beta$; BoLA-DRB1: major histocompatibility complex, class II, DR $\beta$ 1; C1QB: complement component 1, q subcomponent, B chain; CASP1: caspase 1, apoptosis-related cysteine peptidase (interleukin 1, $\beta$, convertase); CCL5: chemokine (C-C motif) ligand 5; CD2: CD2 molecule; CD3E: CD3e molecule, $\epsilon$ (CD3-TCR complex); CD69: CD69 molecule; CD84: CD84 molecule; CD96: CD96 molecule; CTSC: cathepsin C; CTSS: cathepsin S; CXCL10: chemokine (C-X-C motif) ligand 10; CXCR4: chemokine (C-X-C motif) receptor 4; CYBB: cytochrome b-245, $\beta$-polypeptide; FCER1G: Fc fragment of IgE, high affinity I, receptor for; $\gamma$-polypeptide; FCGR3A: Fc fragment of IgG, low affinity IIIa, receptor (CD16a); IFNAR1: interferon ( $\alpha$, $\beta$, and $\omega)$ receptor 1; IL2RG: interleukin 2 receptor, $\gamma$ (severe combined immunodeficiency); IL18: interleukin 18 (interferon-gamma-inducing factor); IRF1: interferon regulatory factor 1; IRF2: interferon regulatory factor 2; IRF8: interferon regulatory factor 8; KLRK1: killer cell lectin-like receptor subfamily K, member 1; MSR1: macrophage scavenger receptor 1; MX1: myxovirus (influenza virus) resistance 1, interferon-inducible protein p78; OAS1: 2',5'-oligoadenylate synthetase 1, 40/46 kDa; PRAP1: prolin-rich acidic protein 1; PRKCB1: protein kinase C, $\beta$; PRKX: protein kinase, X-linked; PSMB8: proteasome (prosome, macropain) subunit, $\beta$-type, 8 (large multifunctional peptidase 7); PSME1: proteasome (prosome, macropain) activator subunit 1 (PA28 $\alpha$ ); PSME2: proteasome (prosome, macropain) activator subunit 2 (PA28 $\beta$ ); PTPRC: protein tyrosine phosphatise, receptor type, C; ST6GAL1: ST6 $\beta$-galactosamide $\alpha$-2,6-sialyltransferase 1; STAT1: signal transducer and activator of transcription 1, $91 \mathrm{kDa}$; STAT2: signal transducer and activator of transcription 2, $113 \mathrm{kDa}$; TAP1: transporter 1, ATP-binding cassette, subfamily B (MDR/TAP); TLR3: Toll-like receptor 3; VCAM1: vascular cell adhesion molecule 1.

might thus control the expression of immune functions and milk protein genes. The increased expression of immune genes in midpregnancy supports a crucial role of immune proteins in mammary tissue development and functional differentiation.

\section{Conclusion}

With respect to the general mechanisms underlying goat mammary gland development, mammary tissue appears to switch from a stromal tissue to a lobulo-alveolar epithelium during the first half of pregnancy. This is shown by the downregulation of adipocyte-specific genes, such as adiponectin (ADIPOQ), and the upregulation of chemokine encoding genes, which are thought to attract phagocytes into the goat mammary gland where they participate in its remodeling. The second half of pregnancy is characterized by MEC proliferation.
As in several other mammals (mice, rabbits, and cows), the secretory activity of the goat mammary gland is only activated after parturition. However, as induction of the differentiation process seems to take place before 46 days of pregnancy, studies of the underlying mechanism would require earlier screening of developmental stages, during the first third of pregnancy.

Genes of immunity that are upregulated during pregnancy (mainly at P70) participate in the remodeling phase of the differentiation process. A subset of these genes is ready to be switched on and provide both the neonate intestine and the mammary tissue of the lactating goat with nonspecific immunity. As they are downregulated during lactation, immune genes expressed in mammary tissue during pregnancy appear to participate in mammary gland development and remodeling during terminal differentiation, rather than having a protective role. 
Finally, this work provides the first comprehensive analysis of gene expression during functional differentiation of ruminant mammary gland, based on microarray technology. However, these data were obtained with whole, heterogeneous mammary tissues. In ruminants, the lobulo-alveolar epithelium develops within a stromal compartment composed of multiple cell types. Molecular cross talk exists between these cell compartments (epithelial and stromal), and gene expression measurements in such heterogeneous tissue makes it difficult to identify the contributions of specific cell types. In addition, they are based on weighted averages of expression levels in different cell populations, the relative abundance of which changes during pregnancy. Therefore, to precisely determine their relative contributions to the functional differentiation process, gene expression analysis should be repeated in defined cell populations. This is currently underway in our laboratory, using powerful new technologies such as laser capture microdissection.

\section{ACKNOWLEDGMENTS}

We thank the UCEA team (INRA, Centre de Recherche de Jouy-en-Josas) for taking care of the animals, Marie-Laure Martin-Magniette (AgroParisTech) for advice on the microarray experimental design, Philippe Bardoux and Cedric Cabau (SIGENAE) for help in GO data publication and gene annotation, and Karine Hugot and Diane Esquerre (CRB-GADIE) for providing the $22 \mathrm{~K}$ bovine oligoarrays. Finally, we thank the three anonymous referees for their helpful suggestions.

\section{DISCLOSURES}

No conflicts of interest are declared by the author(s).

\section{REFERENCES}

1. Akers RM. Lactational physiology: a ruminant animal perspective. Protoplasma 159: 96-111, 1990.

2. Akers RM. Lactogenic hormones: binding sites, mammary growth, secretory cell differentiation, and milk biosynthesis in ruminants. J Dairy Sci 68: 501-519, 1985.

3. Anderson RR, Harness JR, Snead AF, Salah MS. Mammary growth pattern in goats during pregnancy and lactation. J Dairy Sci 64: 427-432, 1981.

4. Anderson SM, Rudolph MC, McManaman JL, Neville MC. Key stages in mammary gland development. Secretory activation in the mammary gland: it's not just about milk protein synthesis! Breast Cancer Res 9: 204-218, 2007.

5. Atabai K, Sheppard D, Werb Z. Roles of the innate immune system in mammary gland remodeling during involution. J Mammary Gland Biol Neoplasia 12: 37-45, 2007.

6. Baldwin RL. Enzymatic activities in mammary glands of several species. J Dairy Sci 49: 1533-1542, 1966.

7. Benjamini Y, Hochberg Y. Controlling the false discovery rate: a practical and powerful approach to multiple testing. J Royal Stat Soc Serie B 47: 289-300, 1995.

8. Bevilacqua C, Helbling JC, Miranda G, Martin P. Translational efficiency of casein transcripts in the mammary tissue of lactating ruminants. Reprod Nutr Dev 5: 567-578, 2006.

9. Bionaz M, Loor JJ. Gene networks driving bovine milk fat synthesis during the lactation cycle. BMC Genomics 9: 366, 2008.

10. Brazma A, Hingamp P, Quackenbush J, Sherlock G, Spellman P, Stoeckert C, Aach J, Ansorge W, Ball CA, Causton HC, Gaasterland T, Glenisson P, Holstege FCP, Kim IF, Markowitz V, Matese JC, Parkinson H, Robinson A, Sarkans U, Schulze-Kremer S, Stewart J, Taylor R, Vilo J, Vingron M. Minimum information about microarray experiment (MIAME) - toward standards for microarray data. Nature Genomics 29: 365-371, 2001.

11. Capuco AV, Connor EE, Wood DL. Regulation of mammary gland sensitivity to thyroid hormones during the transition from pregnancy to lactation. Exp Biol Med (Maywood) 233: 1309-1314, 2008.
12. Cario E, Podolsky DK. Differential alteration in intestinal epithelial cell expression of toll-like receptor 3 (TLR3) and TLR4 in inflammatory bowel disease. Infect Immun 68: 7010-7017, 2000.

13. Cases S, Zhou P, Shillingford JM, Wiseman BS, Fish JD, Angle CS, Hennighausen L, Werb Z, Farese RV. Development of the mammary gland requires DGAT1 expression in stromal and epithelial tissues. Development 131: 3047-3055, 2004.

14. Chanat E, Martin P, and Ollivier-Bousquet M. AlphaS1-casein is required for the efficient transport of beta-casein and kappa-casein from the endoplasmic reticulum to the Golgi apparatus mammary epithelial cells. J Cell Sci 112: 3399-3412, 1999.

15. Choi KM, Barash I, Rhoads RE. Insulin and prolactin synergistically stimulate beta-casein messenger ribonucleic acid translation by cytoplasmic polyadenylation. Mol Endocrinol 18: 1670-1686, 2004.

16. Clarkson RWE, Wayland MT, Lee JH, Freeman T, Watson CJ. Gene expression profiling of mammary gland development reveals putative roles for death receptors and immune mediators in post-lactational regression. Breast Cancer Res 6: R92-R109, 2003.

17. Connor EE, Meyer MJ, Li RW, Van Amburgh ME, Boisclair YR, Capuco AV. Regulation of gene expression in the bovine mammary gland by ovarian steroids. J Dairy Sci 90: E55-E65, 2007.

18. Delmar P, Robin S, Daudin JJ. VarMixt: efficient variance modelling for the differential analysis of replicated gene expression data. Bioinformatics 21: 502-508, 2005.

19. Everts RE, Chavatte-Palmer P, Razzak A, Hue I, Green CA, Oliveira R, Vignon X, Rodriguez-Zas SL, Tian XC, Yang X, Renard JP, Lewin HA. Aberrant gene expression patterns in placentomes are associated with phenotypically normal and abnormal cattle cloned by somatic cell nuclear transfer. Physiol Genomics 33: 65-77, 2008.

20. Finucane KA, McFadden TB, Pond JP, Kennelly JJ, Zhao FQ. Onset of lactation in the bovine mammary gland: gene expression profiling indicates a strong inhibition of gene expression in cell proliferation. Funct Integr Genomics 8: 251-264, 2008.

21. Goudon-Evans V, Lin EY, Pollard JW. Requirement of macrophages and eosinophils and their cytokines/chemokines for mammary gland development. Breast Cancer Res 4: 155-164, 2002.

22. Hennighausen L, Robinson GW. Signaling pathways in mammary gland development. Dev Cell 1: 467-475, 2001.

23. Hennighausen L, Robinson GW. Think globally, act locally: the making of a mouse mammary gland. Genes Dev 12: 449-455, 1998.

24. Hovey RC, McFadden TB, Akers RM. Regulation of mammary gland growth and morphogenesis by the mammary fat pad: a species comparison. J Mammary Gland Biol Neoplasia 4: 53-68, 1999.

25. Hovey RC, Trott JF, Vonderhaar BK. Establishing a framework for the functional mammary gland: from endocrinology to morphology. $J$ Mammary Gland Biol Neoplasia 7: 17-38, 2002.

26. Hu E, Liang P, Spiegelman BM. AdipoQ is a novel adipose-specific gene dysregulated in obesity. J Biol Chem 271: 10697-10703, 1996.

27. Kanazawa T, Kohmoto K. Immunochemical demonstration of alphaS1 and beta casein in mouse mammary glands at early stages of pregnancy. $J$ Histochem Cytochem 50: 257-264, 2002.

28. Kerr MK. Design considerations for efficient and effective microarray studies. Biometrics 59: 822-828, 2003.

29. Kerr MK, Churchill GA. Experimental design for gene expression microarrays. Biostatistics 2: 183-201, 2001.

30. Khaled WT, Read EKC, Nicholson SE, Baxter FO, Brennan AJ, Came PJ, Sprigg N, McKenzie ANJ, Watson CJ. The IL-4/IL-13/Stat6 signalling pathway promotes luminal mammary epithelial cell development. Development 134: 2739-2750, 2007.

31. Mary-Huard T, Picard F, Robin S. Introduction to statistical methods for microarray data analysis. In: Mathematical and Computational Methods in Biology, edited by Hermann. Paris: 2006, p. 56-126.

32. Master SR, Hartman JL, D'Cruz CM, Moody SE, Keiper EA, Ha SI, Cox JD, Belka GK, Chodosh LA. Functional microarray analysis of mammary organogenesis reveals a developmental role in adaptative thermogenesis. Mol Endocrinol 16: 1185-1203, 2002.

33. Mellenberger RW, Bauman DE. Metabolic adaptations during lactogenesis. Fatty acid synthesis in rabbit mammary tissue during pregnancy and lactation. Biochem J 138: 373-379, 1974.

34. Mellenberger RW, Bauman DE, Nelson DR. Metabolic adaptations during lactogenesis. Fatty acid and lactose synthesis in cow mammary tissue. Biochem J 136: 741-748, 1973.

35. Molenaar AJ, Kuys YM, Davis SR, Wilkins RJ, Mead PE, Tweedie JW. Elevation of lactoferrin gene expression in developing, ductal, rest- 
ing, and regressing parenchymal epithelium of the ruminant mammary gland. J Dairy Sci 79: 1198-1208, 1996.

36. Mori S, Nishikawa SI, Yokota Y. Lactation defect in mice lacking the helix-loop-helix inhibitor Id2. EMBO J 19: 5772-5781, 2000.

37. Nakhasi HL, Qasba PK. Quantitation of milk proteins and their mRNAs in rat mammary gland at various stages of gestation and lactation. $J$ Biol Chem 254: 69016-66025, 1979.

38. Naylor MJ, Oakes SR, Gardiner-Garden M, Harris J, Blazek K, Ho TWC, Li FC, Wynick D, Walker AM, Ormandy CJ. Trancriptional changes underlying the secretory activation phase of mammary gland development. Mol Endocrinol 19: 1868-1883, 2005.

39. Neville MC, McFadden TB, Forsyth I. Hormonal regulation of mammary differentiation and milk secretion. J Mammary Gland Biol Neoplasia 7:49-66, 2002.

40. Niranjan B, Buluwela L, Yant J, Perusinghe N, Atherton A, Phippard D, Dale T, Gusterson B, Kamalati T. HGF/SF: a potent cytokine for mammary growth, morphogenesis and development. Development 121 : 2897-2908, 1995.

41. Ogg SL, Weldon AK, Dobbie L, Smith AJH, Mather IH. Expression of butyrophilin (Btna1) in lactating mammary gland is essential for the regulated secretion of milk lipid droplets. Proc Natl Acad Sci USA 101: 10084-10089, 2004.

42. Ollier S, Robert-Granié C, Bernard L, Chilliard Y, Leroux C. Mammary transcriptome analysis of food-deprived lactating goats highlights genes involved in milk secretion and programmed cell death. $J$ Nutr 137: 560-567, 2007.

43. Pedchenko VK, Imagawa W. Pattern of expression of the KGF receptor and its ligands KGF and FGF-10 during postnatal mouse mammary gland development. Mol Reprod Dev 56: 441-447, 2000.

44. Pitelka DR, Hamamoto ST, Duafala JG, Nemanic MK. Cell contacts in the mouse mammary gland - Normal gland in postnatal development. $J$ Cell Biol 56: 797-818, 1973.

45. Proudfoot AEI, Buser R, Borlat F, Alouani S, Soler D, Offord RE, Schroder JM, Power CA, Wells TNC. Amino-terminallys modified RANTES analogous demonstrate differential effects on RANTES receptors. J Biol Chem 274: 32478-32485, 1999.

46. Rainard P, Riollet C. Innate immunity of the bovine mammary gland. Vet Res 37: 369-400, 2006.

47. Robinson GW, McKnight RA, Smith GH, Hennighausen L. Mammary epithelial cells undergo secretory differentiation in cycling virgins but require pregnancy for the establishment of terminal differentiation. Development 121: 2079-2090, 1995.

48. Romagnani P, Annunziato F, Lazzeri E, Cosmi L, Beltrame CL, L, Galli G, Francalanci M, Manetti R, Marra F, Vanini V, Maggi E, Romagnani S. Interferon-inducible protein 10 , monokine induced by interferon gamma, and interferon-inducible T-cell alpha chemoattractant are produced by thymic epithelial cells and attract T-cell receptor (TCR) alpha beta + CD8 + single-positive T cells, TCR gamma delta $+\mathrm{T}$ cells, and natural killer-type cells in human thymus. Blood 97: 601-607, 2001.

49. Rudolph MC, McManaman JL, Hunter L, Phang T, Neville MC. Functional development of the mammary gland: use of expression profiling and trajectory clustering to reveal changes in gene expression during pregnancy, lactation, and involution. J Mammary Gland Biol Neoplasia 8: 287-307, 2003.

50. Rudolph MC, McManaman JL, Phang TL, Russell T, Kominsky DJ, Serkova NJ, Anderson SM, Neville MC. Metabolic regulation in the lactating mammary gland: a lipid synthesizing machine. Physiol Genomics 28: 323-336, 2007.

51. Saeed AI, Sharov V, White J, Li J, Liang W, Bhagabati N, Braisted J, Klapa M, Currier T, Thiagarajan M, Sturn A, Snuffin M, Rezantsev A, Popov D, Ryltsov A, Kostukovich E, Borisovsky I, Liu Z, Vinsavich A, Trush V, Quackenbush J. TM4: a free, open-source system for microarray data management and analysis. Biotechniques 34: 374-378, 2003.

52. Schroeder A, Mueller O, Stocker S, Salowsky R, Leiber M, FGassmann M, Lightfoot S, Menzel W, Granzow M, Ragg T. The RIN: an RNA integrity number for assigning integrity values to RNA measurements. BMC Molecular Biology 7: 3, 2006.

53. Schwertfeger KL, McManaman JL, Palmer CA, Neville MC, Anderson SM. Expression of constitutively activated Akt in the mammary gland leads to excess lipid synthesis during pregnancy and lactation. J Lipid Res 44: 1100-1112, 2003.

54. Sordillo LM, Streicher KL. Mammary gland immunity and mastitis susceptibility. J Mammary Gland Biol Neoplasia 7: 135-146, 2002.

55. Soukas A, Cohen P, Socci ND, Friedman JM. Leptin-specific patterns of gene expression in white adipose tissue. Genes Dev 14: 963-980, 2000.

56. Stein T, Morris JS, Davies CR, Weber-Hall SJ, Duffy MA, Heath VJ, Bell AK, Ferrier RK, Sandilands GP, Gusterson BA. Involution of the mouse mammary gland is associated with an immune cascade and an acute-phase response, involving LBP, CD14 and STAT3. Breast Cancer Res 6: R75-R91, 2004.

57. Suchyta SP, Sipkovsky S, Halgren RG, Kruska R, Elftman M, WeberNielsen M, Vandehaar MJ, Xiao L, Tempelman RJ, Coussens PM. Bovine mammary gene expression profiling using a cDNA microarray enhanced for mammary-specific transcripts. Physiol Genomics 16: 8-18, 2003.

58. Suzuki N, Chen NJ, Millar DG, Suzuki S, Horacek T, Hara H, Bouchard D, Nakanishi K, Penninger JM, Ohashi PS, Yeh WC. IL-1 receptor associated kinase 4 is essential for IL-18 mediated NK and Th1 cell responses. J Immunol 170: 4031-4035, 2003.

59. Swanson EW, Poffenbarger JI. Mammary gland development of dairy heifers during their first gestation. J Dairy Sci 62: 702-714, 1979.

60. Tucker HA. Hormone, mammary growth, lactation: a 41-year perspective. J Dairy Sci 83: 874-884, 2000.

61. Vorbach C, Capecchi MR, Penninger JM. Evolution of the mammary gland from the innate immune system? Bioessays 28: 606-616, 2006.

62. Wang M, Master SR, Chodosh LA. Computational expression deconvolution in a complex mammalian organ. BMC Informatics 7: 328, 2006.

63. Watson CJ. Immune cell regulators in mouse mammary development and involution. J Anim Sci 87, Suppl: 35-42, 2008.

64. Yang Y, Dudoit S, Luu D, Peng V, Ngai J, Speed T. Normalization for cDNA microarray data: a robust composite method addressing single and multiple slide systematic variation. Nucleic Acids Res 30: e15, 2002. 